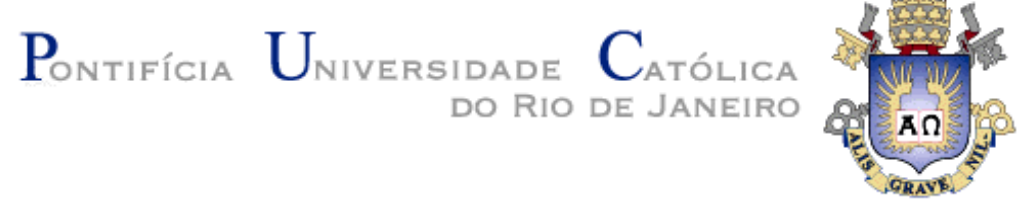

Amanda de Azevedo Stavale

Nanopartículas núcleo-casca de polímeros e surfactantes para formulação de um protetor solar para cabelos

Dissertação de Mestrado

Dissertação apresentada ao Programa de Pós-Graduação em Química da PUC-Rio como requisito parcial para obtenção do grau de Mestre em Química.

Orientadora: Profa. Ana Maria Percebom

Rio de Janeiro

Fevereiro de 2018 


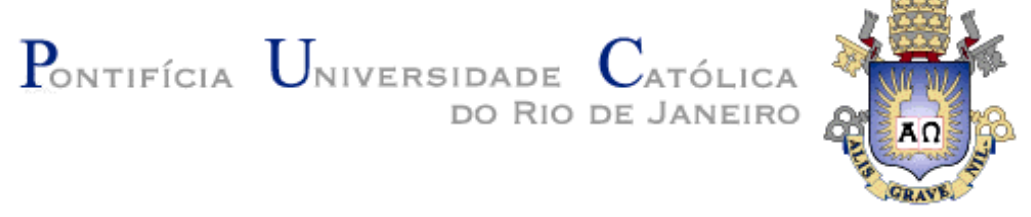

Amanda de Azevedo Stavale

\begin{abstract}
Nanopartículas núcleo-casca de polímeros e surfactantes para formulação de um protetor solar para cabelos
\end{abstract}

Dissertação apresentada como requisito parcial para obtenção do grau de Mestre pelo programa de PósGraduação em Química do Departamento de Química do Centro Técnico Científico da PUC-Rio. Aprovada pela Comissão Examinadora abaixo assinada.

\author{
Profa. Ana Maria Percebom \\ Orientador \\ Departamento de Química PUC-RIO
}

Profa. Letícia Vitorazi

Universidade Federal Fluminense

Prof. Paulo Henrique de Souza Picciani Universidade Federal do Rio de Janeiro

Prof. Jiang Kai

Departamento de Química PUC-RIO

Prof. Márcio da Silveira Carvalho

Coordenador Setorial do Centro

Técnico Científico -PUC-Rio

Rio de Janeiro, 7 de Fevereiro de 2018 
Todos os direitos reservados. É proibida a reprodução total ou parcial do trabalho sem autorização da universidade, da autora e do orientador.

\section{Amanda de Azevedo Stavale}

Graduou-se em Licenciatura em química na UENF (Universidade Estadual do Norte Fluminense) em 2015. Concluiu o mestrado em química na PUCRio (Pontifícia Universidade Católica do Rio de Janeiro) em 2018, atuando na área de físico-química. Participou de diversos congressos na área de química. É professora de nível fundamental II e médio, lecionando aulas de química e ciências.

Ficha Catalográfica

Stavale, Amanda de Azevedo

Nanopartículas núcleo-casca de polímeros e surfactantes para formulação de um protetor solar para cabelos / Amanda de Azevedo Stavale; orientadora: Ana Maria Percebom. - 2018.

63 f.: il. color. ; $30 \mathrm{~cm}$

Dissertação (mestrado)-Pontifícia Universidade Católica do Rio de Janeiro, Departamento de Química, 2018.

Inclui bibliografia

1. Química - Teses. 2. Surfactantes. 3. Cosméticos. 4. Cristais líquidos. 5. Copolímeros dibloco. 6. Coloides. I. Percebom, Ana Maria. II. Pontifícia Universidade Católica do Rio de Janeiro. Departamento de Química. III. Título. 


\section{Agradecimentos}

A Deus, pela encarnação abençoada e pela missão a qual me foi concedida na Terra.

A minha orientadora, Professora Ana Maria Percebom, pelo estímulo, apoio e principalmente por sua grande dedicação em me auxiliar neste trabalho.

A CAPES, a FAPERJ e ao CNPq, pelos auxílios concedidos, sem os quais este trabalho não poderia ser realizado.

A BASF pela doação dos copolímeros dibloco.

Ao CNPEM e ao LNLS pelas análises de SAXS.

Ao LABIO e ao professor Nicolás Rey pelas análises de infravermelho.

Ao Laboratório de Espectroscopia de Biomoléculas e a professora Sônia Louro pelas análises no espectrofluorímetro.

Aos funcionários da PUC-Rio, em especial ao Álvaro, técnico do laboratório de físico-química pelo auxílio na construção da câmara de radiação e a Fátima secretária do departamento, por todo amparo e assistência durante a pós-graduação.

Aos doadores das mechas de cabelo necessárias para este experimento.

Aos professores participantes da banca examinadora.

Ao grupo de pesquisa M\&N Lab, pelo estímulo e estudos em conjunto.

Aos meus familiares, por todo apoio que sempre me foi dado.

Aos meus colegas da PUC-Rio, Cristiane, Elizanne, Guilherme, Igor, Laís e Rafaela, pelo incansável incentivo, conversas e companheirismo nesta grande batalha chamada pós-graduação, vocês ajudaram a torna essa jornada mais leve.

Ao meu marido Leonardo, por não me deixar desistir, por estar sempre ao meu lado, sem você com certeza não teria chegado ao fim deste curso.

Ao meu pai Jarcy de Azevedo (in memorian) por guiar minha jornada.

A minha mãe do coração Vera Regina (in memorian) por ter acreditado no meu potencial, me acolhido e me ensinado a viver da mais maneira correta possível. 


\section{Resumo}

Stavale, Amanda de Azevedo; Percebom, Ana Maria (orientador). Nanopartículas núcleo-casca de polímeros e surfactantes para formulação de um protetor solar para cabelos. Rio de Janeiro, 2018. 63p. Dissertação de Mestrado - Departamento de Química, Pontifícia Universidade Católica do Rio de Janeiro.

O presente estudo investiga a estrutura e a potencial aplicação de nanopartículas formadas por copolímeros que possuem um bloco neutro e outro bloco aniônico combinados a um surfactante catiônico. Em água, os blocos aniônicos se complexam eletrostaticamente às micelas de surfactante, interconectando-as e formando um núcleo concentrado, que pode até apresentar estrutura líquido-cristalina. Os blocos neutros são hidrofílicos e por isso formam uma casca que estabiliza as nanopartículas em água. Devido à formação do núcleo concentrado de micelas, espera-se que estas nanopartículas sejam capazes de incorporar uma maior quantidade de moléculas hidrofóbicas em comparação a micelas de surfactante puro na mesma concentração. Os resultados indicam que quanto mais longo é o bloco aniônico, mais alta é a incorporação das moléculas hidrofóbicas. Por outro lado, o bloco neutro tem um papel importante para aumentar a estabilidade das nanopartículas em meio aquoso. A incorporação de moléculas hidrofóbicas no núcleo das nanopartículas causa alterações na organização das micelas, levando à formação de diferentes estruturas líquido-cristalinas ou a alterações nas distâncias de correlação. Com base nas propriedades das nanopartículas, foi proposta uma formulação aquosa capaz de incorporar uma quantidade significativa de um filtro solar orgânico. Com os resultados obtidos para esta formulação, foi possível demonstrar sua eficácia em evitar a degradação de cabelos por irradiação ultravioleta, o que torna este sistema um candidato de alto potencial para aplicação na indústria de cosméticos.

\section{Palavras-chave}

Surfactantes; cosméticos; cristais líquidos; copolímeros dibloco; coloides 


\section{Abstract}

Stavale, Amanda de Azevedo; Percebom, Ana Maria (Advisor). Core-shell nanoparticles of polymers and surfactants for the formulation of a sunscreen for hair. Rio de Janeiro, 2018. 63p. Dissertação de Mestrado Departamento de Química, Pontifícia Universidade Católica do Rio de Janeiro.

The present study investigates the structure and potential application of core-shell nanoparticles formed by block copolymers (consisted of an anionic and a neutral blocks) and a cationic surfactant. In water, the anionic blocks electrostatically complex to the surfactant micelles, interconnecting them and forming a concentrated nucleus, which may form even liquid-crystalline structures. Because the neutral blocks are hydrophilic, they form a shell which stabilizes the nanoparticles in water. The concentrated nuclei of micelles are expected to uptake a higher amount of hydrophobic molecules than the regular micelles of pure surfactant in the same concentration. The longer is the anionic block forming the nucleus, the higher is the uptake of hydrophobic substances. On the other hand, the neutral block plays a key role to increase nanoparticle stability in aqueous medium. The uptake of hydrophobic molecules increased the ordering of the micelles in the nucleus, leading either to the formation of different liquid-crystalline structures or to variations in the correlation distances. Taking these results in to account, we proposed an aqueous formulation with a considerable uptake capacity of an organic sunscreen. The results obtained for this formulation demonstrate its efficacy to avoid hair degradation by ultraviolet radiation exposition, which make this system a potential candidate for applications in the cosmetic industry.

\section{Keywords}

Surfactants; cosmetics; liquid crystals, Diblock copolymers; colloids 


\section{Sumário}

1. INTRODUÇÃO

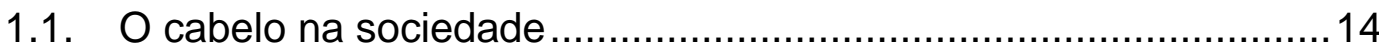

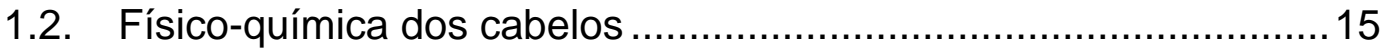

1.3. Radiação ultravioleta e fotodegradação ......................................17

1.4. Protetor Solar para Cabelos ................................................... 18

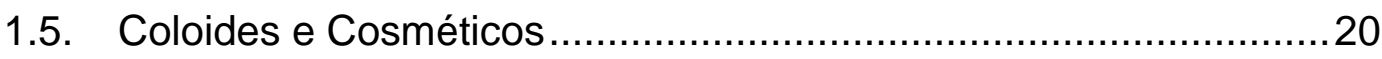

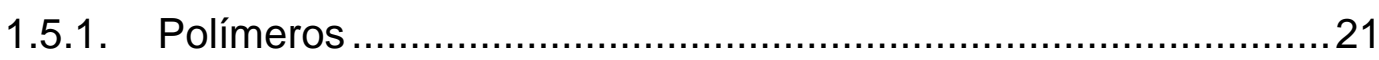

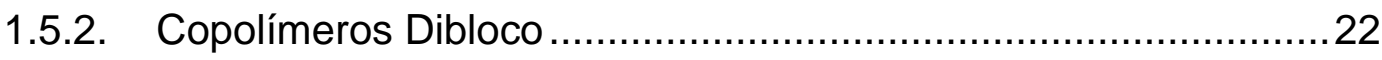

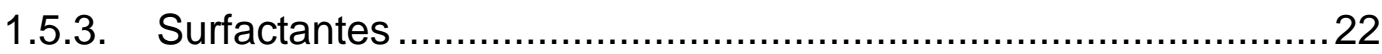

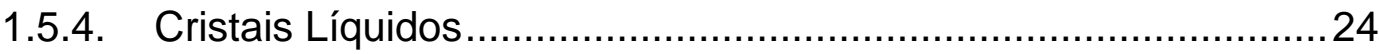

1.5.5. Nanopartículas núcleo-casca de copolímeros dibloco e

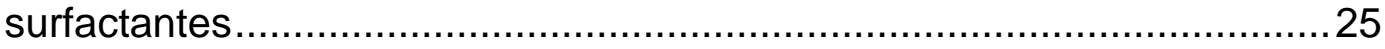

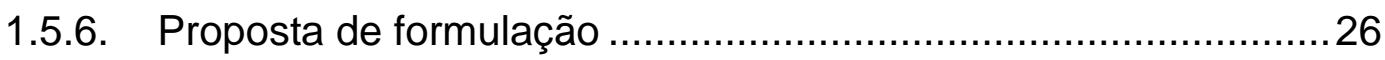

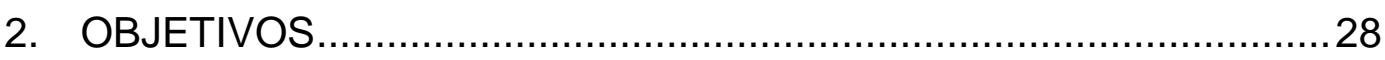

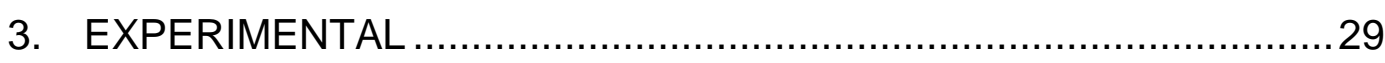

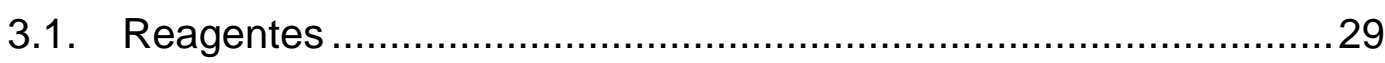

3.2. Preparação das nanopartículas núcleo-casca................................29

3.3. Incorporação das moléculas hidrofóbicas de filtro solar. .................30

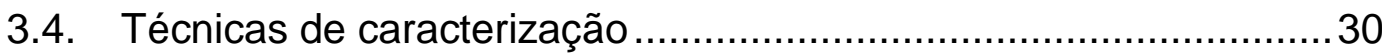

3.4.1. Espalhamento dinâmico de luz (DLS) …................................. 30

3.4.2. Espalhamento de raios $X$ a baixos ângulos (SAXS) ...................31

3.5. Verificação do potencial da amostra como formulação de um produto de proteção solar para cabelos. ..................................................33

3.5.1. Espectroscopia na região Ultravioleta e Visível ..........................33

3.5.2. Espectroscopia na região do Infravermelho ................................ 35

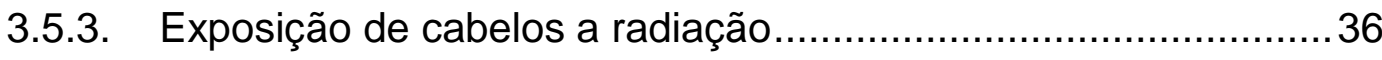

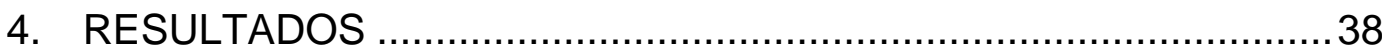

4.1. Incorporação do octilmetoxicinamato nas nanopartículas núcleo-

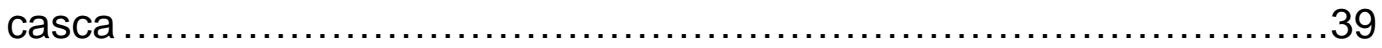

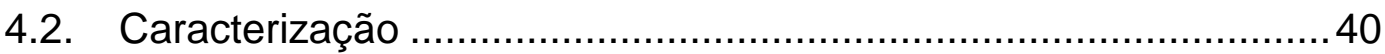

4.2.1. Resultados de DLS

4.2.2. Resultados de SAXS ......................................................... 42

4.3. Verificação do potencial como formulação de um produto de proteção solar para cabelos 
4.3.1. Aspectos gerais da formulação por observação visual ...............48

4.3.2. Avaliação de deposição sobre superfície hidrofílica..................48

4.3.3. Cálculo do fator de protetor solar (FPS) in vitro .......................50

4.3.4. Avaliação da proteção contra radiação em cabelos humanos ....53

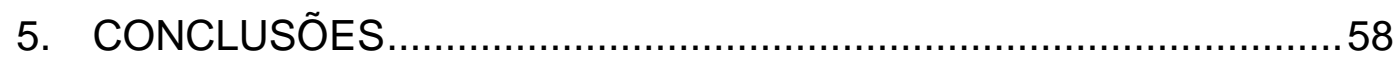

6. REFERÊNCIAS BIBLIOGRÁFICAS ........................................6 60 


\section{Lista de figuras}

Figura 1: Principais regiões do fio de cabelo humano.

Adaptado da referência ${ }^{5}$ 16

Figura 2: Reação de fotoxidação do aminoácido cistina ${ }^{5}$

Figura 3: Estrutura molecular do filtro solar octilmetoxicinamato.

Figura 4: Estruturas moleculares dos polímeros: (a) PEO e (b) PMAA...22

Figura 5: Estrutura molecular do copolímero dibloco utilizado neste trabalho, poli(óxido de etileno)-b-poli(ácido metacrílico),

PEOm-b-PMAAn.

Figura 6: Estrutura molecular do surfactante catiônico cloreto de hexadeciltrimetilamônio

Figura 7: Formação e estrutura das nanopartículas núcleo-casca.

Adaptado da referência ${ }^{20}$ .26

Figura 8: Câmara de radiação ultravioleta.

Figura 9: Espectro de emissão da fonte utilizada na

câmara de radiação.

Figura 10: Curvas de distribuição de diâmetro hidrodinâmico de amostras de diferentes complexos em meio aquoso, na ausência (linha sólida) ou na presença da concentração máxima de octilmetoxicinamato (linha tracejada). Os números indicam as unidades monoméricas do bloco de PEO e PMAA (m:n), respectivamente, dos copolímeros que formam cada um dos complexos.

Figura 11: Resultados de SAXS para amostras de nanopartículas do complexo $\mathrm{PEO}_{698}$-b-PMAA $477-\mathrm{CTAC}$ em água, com e sem a adição de octilmetoxicinamato.

Figura 12: Resultados de SAXS para amostras de nanopartículas do

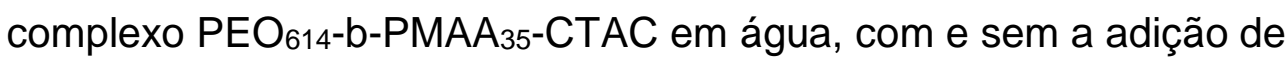
octilmetoxicinamato.

Figura 13: Resultados de SAXS para amostras de nanopartículas do complexo $\mathrm{PEO}_{25}$-b-PMAA 35 -CTAC em água, com e sem a adição de octilmetoxicinamato.

Figura 14: Representação da transição de fases que ocorre devido à reorganização das micelas no interior das nanopartículas núcleo-casca: 
(a) fase cúbica Pm3n antes da adição de octilmetoxicinamato, (b) fase hexagonal após a adição de octilmetoxicinamato.

Adaptado da referência ${ }^{31}$

Figura 15: Resultados de SAXS para as amostras de nanopartículas do complexo $\mathrm{PEO}_{698}$-b-PMAA477-CTAC em água, com octilmetoxicinamato a diferentes concentrações.

Figura 16: Resultados de SAXS para as nanopartículas do complexo PEO698-b-PMAA477 com a adição de octilmetoxicinamato no intervalo de sessenta dias.

Figura 17: Espectro de absorção resultante do teste de deposição sobre um substrato hidrofílico.

Figura 18: Espectro de absorbância normalizada de amostras contendo: A - nanopartículas do complexo PEO ${ }_{698}$-b-PMAA477-CTAC a 2,5\% $(\mathrm{m} / \mathrm{m})$ em água; $B$ - amostra $A$ após adição de $0,33 \%(\mathrm{~m} / \mathrm{m})$ de octilmetoxicinamato, seguida de diluição a 25 vezes; $C$ - amostra $A$ após após adição de $0,33 \%(\mathrm{~m} / \mathrm{m})$ de octilmetoxicinamato, seguida de diluição 125 vezes.

Figura 19: Espectro de FTIR de mechas de cabelo ante e após aplicação da formulação de protetor solar 54

Figura 20: Valores do aumento relativo na razão entre as absorbâncias das bandas de ácido cisteico $\left(1042 \mathrm{~cm}^{-1}\right)$ e $\mathrm{CH}_{2}\left(1450 \mathrm{~cm}^{-1}\right)$ após diferentes tratamentos. 


\section{Lista de tabelas}

Tabela 1: Composição média de aminoácidos do cabelo e da cutícula ${ }^{3}$

Tabela 2: Porcentagem de incorporação máxima do filtro solar hidrofóbico nas nanopartículas núcleo-casca formadas pelos diferentes complexos.

Tabela 3: Valores de diâmetro hidrodinâmico médio (Dh) de nanopartículas e os respectivos desvios-padrão (DP) das tripilicatas obtidos por medidas de DLS de diferentes complexos, antes e após a adição da concentração máxima de filtro solar. .42

Tabela 4: Valores de EE x I normalizados para o cálculo do FPS.

Adaptado da referência 32

Tabela 5: Valores utilizados para o cálculo do fator de proteção solar

Tabela 6: Principais bandas do espectro de absorção do infravermelho a serem acompanhadas nos espectros deste trabalho. 55 


\section{Lista de abreviaturas}

UV - Ultravioleta

FTIR - Fourier-transform infrared spectroscopy

ATR - Attenuated total reflectance

SAXS - Small-Angle X-Ray Scattering

DLS - Dynamic Light Scattering

IV - Infravermelho

PEO - Poli(óxido de etileno)

PMAA - Poli(ácido metacrílico)

PEOm-b-PMAA - Copolímero dibloco poli(óxido de etileno)-b-poli(ácido metacrílico), onde $\mathrm{m}$ é o número de comonômero de óxido de etileno e $\mathrm{n}$ é o número de comonômeros de ácido metacrílico

CTAC - Cloreto de cetiltrimetilamônio

cmc - Concentração micelar crítica

DNA - Ácido desoxirribonucleico

FPS - Fator de proteção solar 
Resiliência é ir a guerra e voltar, é sentar com seus demônios numa mesa de bar e conversar, é apanhar de todo o lado e levantar, é ter espírito boxeador, dar ganchos de direita nas dificuldades e nocautear a própria dor. É quem sete vezes cai e levanta oito, é ter um alma-água, que se adapta ao co(r)po em que estiver, da melhor forma que puder.

João Doederlein 


\section{1.}

\section{INTRODUÇÃO}

\section{1.}

\section{O cabelo na sociedade}

A história dos mamíferos testemunha a importância dos pelos e cabelos, que permitiram a sobrevivência a frios noturnos de grandes altitudes, além de servir como proteção para a pele. Os seres humanos são uma espécie especial, que ao longo da história começou a apresentar uma relação um pouco diferente com o cabelo. Atualmente, a importância do cabelo foi reduzida principalmente à estética, apesar de ainda desempenhar importante papel fisiológico na proteção do crânio contra as trocas excessivas de calor com o ambiente ${ }^{1}$.

Devido ao envelhecimento, embelezamento e até à moda, o interesse pelos cabelos por parte da indústria de cosméticos, de pesquisadores acadêmicos e dos consumidores tem aumentado continuamente, valorizando cada vez mais os estudos envolvendo este tecido.

Mesmo sendo considerado um componente meramente estético para muitos, o cabelo apresenta grande importância no fator psicológico das pessoas, porque está diretamente ligado à autoestima. Um grande exemplo é o caso de pessoas que têm perda de cabelo, alopecia, como efeito colateral de tratamentos quimioterápicos afetando diretamente sua autoimagem de pessoa adoecida e o seu preparo psicológico, que é tão importante para sua recuperação ${ }^{2}$.

Além disso, qualquer pessoa pode notar a importância do cabelo na sociedade, simplesmente observando o número de salões de beleza nas cidades e a grande variedade de tipos e marcas de produtos capilares nas prateleiras de lojas e supermercados. Isto vale já não só para o público feminino, uma vez que o número de barbearias tem crescido cada vez mais, nas quais, além de cuidar dos cabelos, os homens procuram também tratamentos para barbas.

Os consumidores atuais tomam cada dia mais cuidado com a 
proteção da pele contra os raios solares nocivos, e a ideia de proteger cabelos ainda é relativamente nova, mas está sendo cada vez mais difundida no mercado. Isto porque os consumidores vêm notando que a exposição prolongada ao sol torna o cabelo quebradiço, difícil de pentear, e muda sua textura, causando então grande prejuízo à tão valorizada estética ${ }^{3}$.

\section{2.}

\section{Físico-química dos cabelos}

O cabelo humano é principalmente formado por um grupo de proteínas denominadas a-queratinas, que diferem de outras proteínas por seu alto teor de pontes de dissulfeto (S-S) provenientes do aminoácido cistina. Quimicamente, cerca de $90 \%$, em massa seca, do cabelo consiste em proteínas cuja composição média de aminoácidos está apresentada na Tabela 1. Os outros $10 \%$ estão distribuídos entre lipídios (4\%), açúcares (1\%), cinza $(0,5 \%)$, zinco (200 ppm) e melanina (4\%). Entretanto, estes valores podem variar de acordo com a idade, sexo e cor ${ }^{3}$.

Tabela 1: Composição média de aminoácidos do cabelo e da cutícula ${ }^{4}$

\begin{tabular}{cc}
\hline Aminoácido & Cabelo (Quantidade residual -\%) \\
\hline Ácido cisteico & 0,34 \\
\hline Ácido aspártico & 5,77 \\
\hline Treonina & 7,45 \\
\hline Serina & 11,52 \\
\hline Ácido glutâmico & 12,95 \\
\hline Prolina & 6,80 \\
\hline Glicina & 6,11 \\
\hline Alanina & 4,62 \\
\hline Valina & 4,98 \\
\hline Meia-cistina & 16,73 \\
\hline Metionina & 0,21 \\
\hline Isoleucina & 2,54 \\
\hline Leucina & 6,49 \\
\hline Tirosina & 2,14 \\
\hline Fenilalanina & 1,65 \\
\hline Lisina & 2,49 \\
\hline Histidina & 0,71 \\
\hline Arginina & 6,51 \\
\hline Triptofano & 1,00 \\
\hline
\end{tabular}

Estruturalmente, o fio do cabelo possui três componentes principais: 
a cutícula (10\% da fibra), o córtex ( $88 \%$ da fibra) e o complexo da membrana celular ( $2 \%$ da fibra), conforme esquematizado na Figura $1^{5}$.

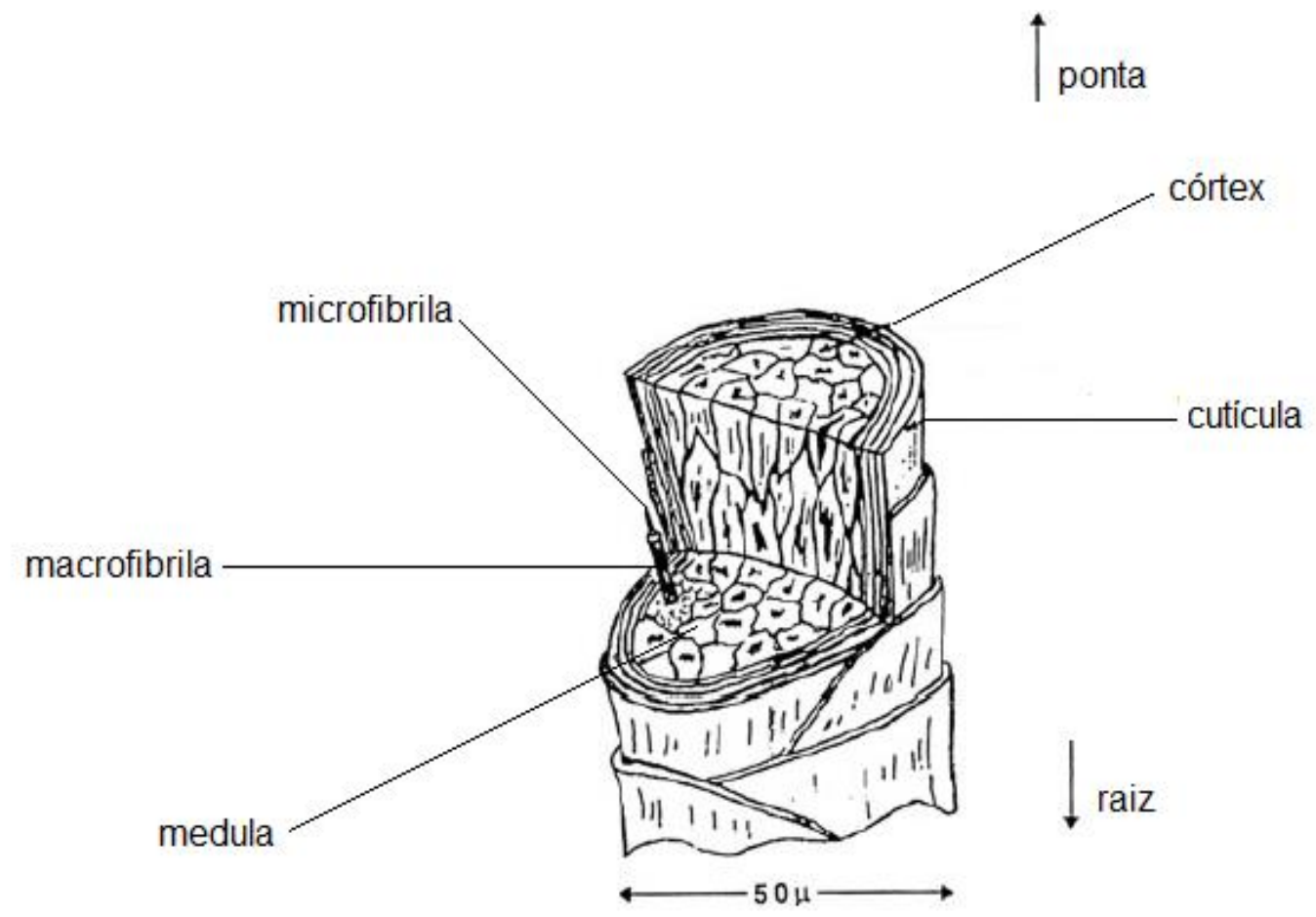

Figura 1: Principais regiões do fio de cabelo humano. Adaptado da referência ${ }^{5}$.

A cutícula, é a parte mais externa do fio e é responsável pela proteção das células, sua estrutura é formada por escamas que se posicionam como telhas, e exerce a função de regular a entrada e saída de água, permitindo manter as propriedades físicas da fibra capilar. A camada mais externa da cutícula é formada pelo ácido 18 - metil eicosanoico, um lipídio estrutural que é ligado à cutícula através de uma ligação tio éster. A oxidação desta ligação torna a superfície do cabelo mais negativa e hidrofílica e facilita a abertura da escama, podendo deixar o córtex mais exposto ${ }^{5}$.

O complexo da membrana celular é o responsável por unir as células do córtex às cuticulares adjacentes. O córtex é formado por macrofibrilas de queratina alinhadas na direção do fio e é responsável por garantir a resistência mecânica do cabelo. Por isso, a degradação de suas proteínas leva a uma maior fragilidade. No córtex são abrigados os grânulos de melanina, responsáveis pela cor e foto-proteção natural do cabelo, porque 
absorvem grande parte da radiação de luz visível e ultravioleta. Por isso, a degradação dos grânulos de melanina leva a alterações na coloração dos cabelos ${ }^{6}$.

\section{3.}

\section{Radiação ultravioleta e fotodegradação}

A radiação ultravioleta (UV) compreende uma faixa de comprimentos de onda que vão desde 100 a 400 nm, classificada em três regiões: UVA (315-400 nm), UVB (280-315 nm) e UVC (100-280 nm). As radiações UVA e UVB trazem benefícios para os seres humanos, pois auxiliam na saúde, bem-estar, e são importantes para a sobrevivência. Entretanto, quando a exposição é intensa e por tempo prolongado, podem ocasionar malefícios para os tecidos externos do corpo humano, como pele e cabelos. Na pele, a radiação permeia e leva a alterações na espessura da epiderme, modificando a pigmentação, causando lesões no ácido desoxirribonucleico (DNA), e alterações nas fibras elásticas ${ }^{6}$. Sabe-se que a exposição à radiação ultravioleta (UV) danifica a estrutura do cabelo, mas como se trata de um tecido morto, não ocorre regeneração nas fibras deterioradas 7 . Desse modo os efeitos causados pela radiação UV na estrutura são acumulativos, irreversíveis e associados a outros fatores que aceleram as modificações estruturais.

O cabelo humano está sujeito a várias reações, e entre elas estão as reações de oxidação. A oxidação fotoquímica ocorre através da exposição do cabelo à radiação de fontes artificiais (câmaras de bronzeamento) ou naturais (sol). Geralmente, a cutícula é mais afetada que o córtex por ser uma camada mais externa que recebe maior intensidade de radiação. As queratinas são transparentes à radiação UVA e visível que, portanto, é transmitida e penetra significativamente o córtex. Lá a radiação UVA e visível será absorvida pelos grânulos de melanina, causando sua fotodegradação, o que leva a mudanças de cor do cabelo. Por outro lado, as queratinas absorvem radiação UVB, causando sua degradação e a consequente perda de proteína e resistência mecânica. Como sua 
intensidade diminui exponencialmente conforme é absorvida, a radiação UVB afeta mais as camadas mais externas do fio de cabelo ${ }^{8}$. Em resumo, UVB é a radiação responsável por tornar os cabelos mais quebradiços e finos e por modificar sua superfície e textura, enquanto a radiação UVA e visível é responsável pelo clareamento dos fios ${ }^{7}$.

A fotodegradação por radiação ultravioleta, que atinge tanto as queratinas quanto os grânulos de melanina, ocorre principalmente através de um mecanismo de fotooxidação que diferente da oxidação, quebra as ligações C-S da cistina levando à formação de uma molécula de ácido cisteico para cada molécula de cistina, este reação pode ser melhor visualizada na figura 2 .<smiles>CC(C)C(=O)OC(=O)[C@@H](N)CSSO[C@@H](N)CSSC[C@H](N)C(=O)O</smiles>

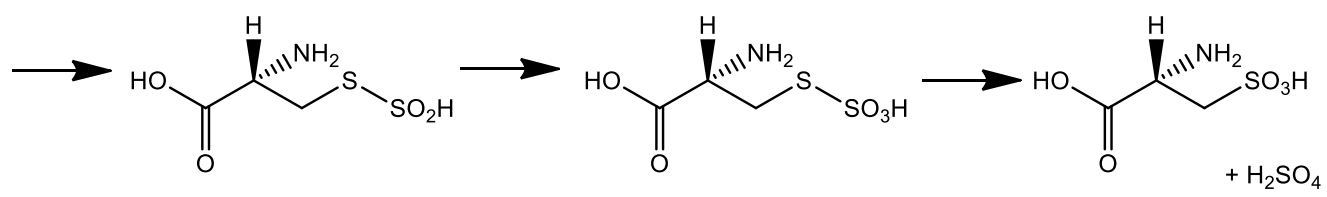

Figura 2: Reação de fotoxidação do aminoácido cistina ${ }^{5}$.

\section{4 .}

\section{Protetor Solar para Cabelos}

Uma dificuldade encontrada por consumidores que desejam proteger os cabelos contra a radiação UV é que as formulações desenvolvidas que contém filtro solares são, em sua maioria, apenas para aplicação na pele. No cenário atual já existem alguns produtos que podem ser utilizados para a pele e cabelos, ou especificamente em cabelos. Estes têm como característica a presença de moléculas catiônicas, para favorecer a interação com a superfície negativa da cutícula do cabelo, promovendo maior aderência do produto nos fios ${ }^{9}$.

Em grande parte dos produtos comercializados atualmente é comum observar a presença de óleo de girassol como um dos ingredientes 
principais de uma emulsão. Isto porque ele é muito utilizado na cosmetologia por conter vitamina $E$, que é muito visada por sua propriedade antioxidante ${ }^{10}$. Entretanto, a maior parte dos produtos não apresenta princípios ativos que realmente apresente a função de filtrar a radiação ultravioleta, uma vez que não há exigências dos órgãos controladores para que produtos capilares reportem o seu valor de fator de proteção solar (FPS), como há para os produtos de pele.

Os filtros solares podem ser classificados como orgânicos (também conhecidos como filtros químicos) ou inorgânicos (também conhecidos como filtros físicos). Os filtros orgânicos são compostos aromáticos com grupos carboxílicos e um grupo doador de elétrons em posição orto ou para. Eles absorvem radiação UV porque excitam os elétrons do orbital $\pi$ HOMO para o $\pi^{*}$ LUMO. Ao retornar ao estado inicial, a energia é liberada na forma de calor e pode causar ou não a degradação da molécula ${ }^{11}$. Devido a sua estrutura molecular, os filtros orgânicos são hidrofóbicos e, portanto, insolúveis ou muito pouco solúveis em água. Um exemplo é o filtro solar químico octilmetoxicinamato, utilizado no presente trabalho e também conhecido pela Nomenclatura Internacional de Ingredientes de Cosméticos (do inglês, INCl) como ethylhexyl methoxycinnamate, ou ainda pelo nome comercial Uvinul® MC 80. O octilmetoxicinamato é aprovado pelas principais agências regulatórias de todo o mundo, sendo o filtro UVB mais utilizado nos produtos comerciais para pele. Esta substância é um óleo e através da sua estrutura molecular, Figura 3, é possível compreender seu caráter hidrofóbico em virtude do anel aromático, da cadeia alquílica e do grupo éster ${ }^{12}$. O caráter hidrofóbico dos filtros orgânicos exige que a maioria dos produtos de proteção solar seja na forma de emulsões ou cremes, que apresentam alta viscosidade. Por isso, este tipo de produto geralmente não é bem aceito pelos os consumidores que vão utilizá-lo durante a exposição ao sol, além de ser de mais difícil aplicação uniforme em todos os fios. 


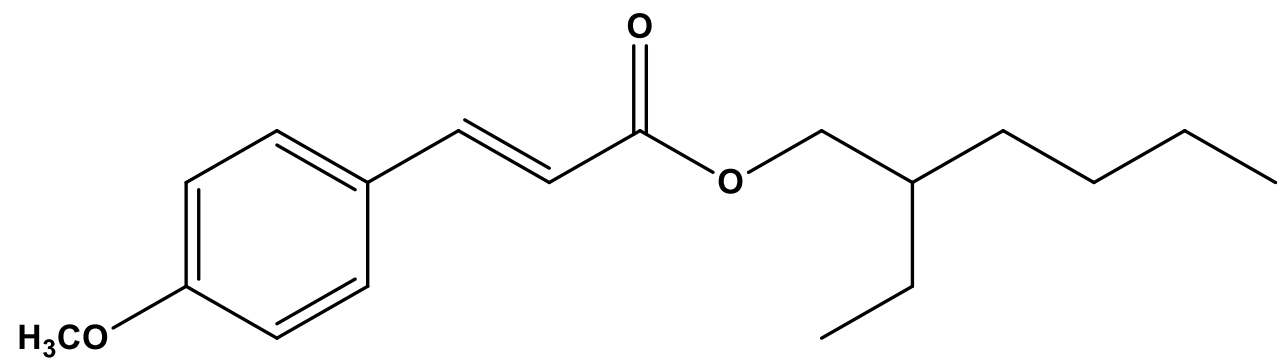

Figura 3: Estrutura molecular do filtro solar octilmetoxicinamato.

Por sua vez, os filtros inorgânicos constituem-se principalmente de nanopartículas de $\mathrm{ZnO}$ ou de $\mathrm{TiO}_{2}$ e não envolvem processo de absorção de radiação, mas sim de espalhamento, como se refletissem a radiação que atinge as nanopartículas, impedindo-a de atingir a superfície a ser protegida ${ }^{11}$. Por apresentar menos interações químicas com a pele, este filtro é muito utilizado em produtos para crianças ou pessoas que possuem algum tipo de sensibilidade na pele. Dentre suas desvantagens estão o custo elevado, o fato de deixar a superfície esbranquiçada e de ser de difícil remoção.

\section{5.}

\section{Coloides e Cosméticos}

A tecnologia de cosméticos está diretamente relacionada à físicoquímica de coloides e Interfaces, que é amplamente utilizada para promover o preparo adequado de formulações de diferentes estruturas coloidais (emulsões, vesículas, cristais líquidos, etc.), melhorar a estabilidade do produto e controlar as propriedades reológicas e sensoriais do sistema. O conhecimento mais aprofundado através da caracterização estrutural dos coloides possibilita também o emprego dos cosméticos para funções mais específicas. Um exemplo é a liberação ou deposição de determinados ingredientes ativos em tecidos ou situações específicas. Este controle das funções dos produtos permite a obtenção de cosméticos com alta tecnologia que atendam às novas exigências dos consumidores. Dentre os sistemas de maior importância na área de coloides e que são amplamente utilizados na área de cosméticos, podemos destacar os 
polímeros e surfactantes, que também serão empregados no presente trabalho.

\subsection{1.}

\section{Polímeros}

Polímeros são macromoléculas formadas por repetidas unidades, ligadas covalentemente, e denominadas meros. As características de um polímero são determinadas principalmente pelo seu tamanho, estrutura química e interações intra- e intermoleculares. Suas massas molares geralmente são da ordem de $10^{3}$ a $10^{7} \mathrm{~g} \mathrm{~mol}^{-1}$, sendo determinadas pelo modo de preparo do polímero ${ }^{13}$.

Polímeros podem ser classificados como neutros ou iônicos (polieletrólitos catiônicos ou aniônicos) de acordo com a ausência ou presença de cargas em seus meros.

Os polímeros estão presentes em diversos produtos do cotidiano e são amplamente utilizados em cosméticos, para modificar a viscosidade ou aumentar a estabilidade (tempo de prateleira). Também podem atuar em superfícies, como é o caso de alguns condicionadores que possuem polímeros catiônicos que se depositam nos cabelos, neutralizando as cargas negativas da cutícula e diminuindo a repulsão eletrostática que causa o que os consumidores chamam de frizz, além de facilitar o pentear e garantir uma textura mais agradável ao toque ${ }^{14}$. A Figura 4 mostra exemplos de estruturas moleculares de alguns polímeros que são relevantes para esta dissertação. O poli(óxido de etileno), PEO, é um exemplo de polímero neutro hidrofílico linear, enquanto o poli(ácido metacrílico), PMAA, é um exemplo de polieletrólito aniônico linear. 
<smiles>CC(C)(C)CCOC(C)(C)C</smiles>

(a)

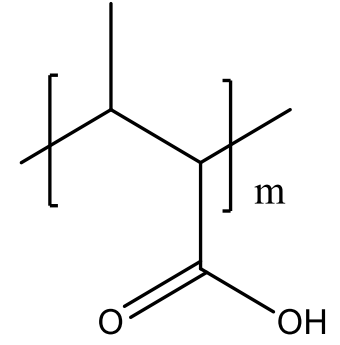

(b)

Figura 4: Estruturas moleculares dos polímeros: (a) PEO e (b) PMAA.

\section{5 .2$.}

\section{Copolímeros Dibloco}

Existem vários tipos de classificação de polímeros conforme a distribuição dos meros. Os polímeros podem ser lineares, ramificados ou reticulados e também podem ter mais de um tipo de unidade monomérica, os chamados copolímeros. Quando os copolímeros são formados por dois blocos de cadeias - cada uma formado por um tipo de comonômero - que são ligadas covalentemente entre $\mathrm{si}$, temos os chamados copolímeros dibloco. Na Figura 5 é apresentada a estrutura molecular do copolímero dibloco utilizado neste trabalho, o poli(óxido de etileno)- $b$-poli(ácido metacrílico), ou PEOm-b-PMAAn. Os subindices $m$ e $n$ indicam os graus de polimerização dos seus respectivos blocos.

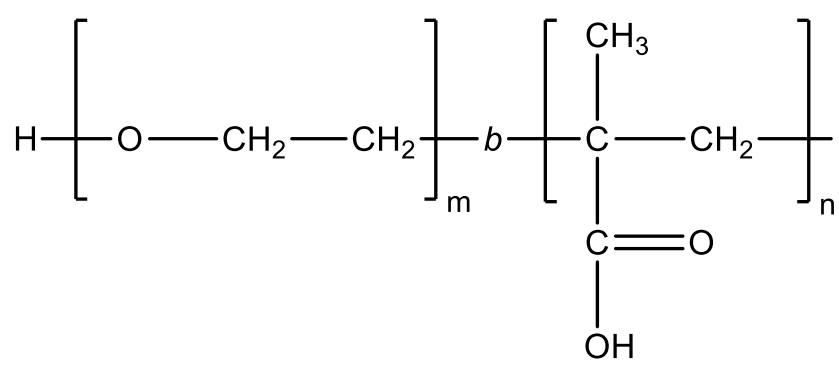

Figura 5: Estrutura molecular do copolímero dibloco utilizado neste trabalho, poli(óxido de etileno)b-poli(ácido metacrílico), PEOm-b-PMAAn.

\subsection{3.}

\section{Surfactantes}

A palavra surfactante tem como origem o fato de que esta substância 
é ativa em superfícies (do inglês, surface $=$ superfície; e active $=$ ativo) $\mathrm{e}$ isto ocorre porque as moléculas de surfactantes apresentam uma parte hidrofílica e outra parte hidrofóbica em sua estrutura. Por isso, são moléculas muito particulares no mundo da Química, apresentando afinidade tanto por substâncias apolares quanto polares, ou seja, elas possuem um caráter anfifílico ${ }^{15}$.

Quando as moléculas de surfactante são adicionadas a uma solução aquosa, parte se dissolve no meio e parte se posiciona nas interfaces (com o ar ou com o recipiente sólido) reduzindo assim a tensão interfacial do líquido. Com o aumento da concentração de surfactante, será atingida uma situação em que não será mais possível que as moléculas se solubilizem individualmente no meio e nem se posicionem mais na interface. Nesta concentração definida, as moléculas passam a se autoassociar em agregados chamados de micelas, nas quais, o contato entre a parte hidrofóbica do surfactante e as moléculas de água é reduzido. Esta concentração em que este fenômeno se inicia é chamada de concentração micelar crítica (cmc). Devido ao interior das micelas ser formado pela porção hidrofóbica das moléculas de surfactante, elas podem ser capazes de solubilizar substâncias hidrofóbicas, como óleos, em seu interior ${ }^{15}$.

Todas essas características permitem que os surfactantes sejam utilizados em diversas aplicações importantes para a área de cosméticos, como a formação de emulsões, espumas, suspensões, microemulsões ou propiciando a formação de filmes e detergência de superfícies ${ }^{16}$.

Existem diferentes tipos de surfactantes, entre eles, neutros, catiônicos, aniônicos e zwitteriônicos. O presente trabalho irá utilizar o surfactante catiônico cloreto de hexadeciltrimetilamônio que tem sua estrutura representada na Figura 6. Este surfactante é amplamente utilizado na indústria de cosméticos, principalmente para condicionadores de cabelos, com ou sem enxágue, e é conhecido como cetrimonium chloride pela nomenclatura INCI. 


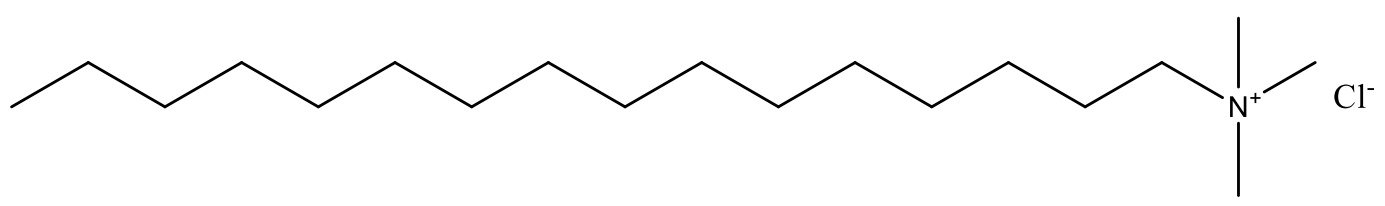

Figura 6: Estrutura molecular do surfactante catiônico cloreto de hexadeciltrimetilamônio

\subsection{4.}

\section{Cristais Líquidos}

O termo "cristal líquido" designa um estado da matéria que é intermediário ao estado sólido cristalino e ao estado líquido isotrópico. Um cristal líquido é um verdadeiro líquido, porque flui sob cisalhamento e pode tomar a forma de seu recipiente ${ }^{17}$. Entretanto, ele é chamado de cristal porque possui uma estrutura altamente ordenada.

Quando a concentração de surfactante em água continua a ser aumentada após atingir a cmc, ela pode chegar a uma situação em que a fração volumétrica de micelas é tão alta que elas começam a se organizar, formando os cristais líquidos liotrópicos. Neste tipo de cristal líquidos, as transições de fase ocorrem de acordo com as interações com o solvente. Entre os tipos de fase líquido-cristalinas liotrópicas mais comuns estão as fases: cúbica, hexagonal e lamelar, mas há outras intermediárias ${ }^{15}$. As propriedades reológicas dos cristais-líquidos liotrópicos com diferentes estruturas os tornam muito interessantes para a indústria de cosméticos. Por exemplo, a fase lamelar é amplamente empregada em produtos que necessitam apresentar uma alta tensão de escoamento, porém que reduzem a viscosidade a altas taxas de cisalhamento. Por isso é muito encontrada em diferentes tipos de cremes cosméticos para pele e cabelo.

Devido à compactação de um grande número de micelas no seu interior, os cristais-líquidos também podem ser muito úteis para dissolver substâncias hidrofóbicas e até mesmo para uma liberação controlada das mesmas. Apesar de fluírem, os cristais-líquidos ainda apresentam viscosidade alta, o que pode ser uma limitação para algumas aplicações. Entretanto, é possível reverter esta situação através da obtenção de dispersões das fases líquido-cristalinas, como é o caso das cubossomas e lipossomas (dispersões de fases cúbicas e lamelares, respectivamente). ${ }^{18}$ 
O presente trabalho abordará uma forma alternativa de empregar os cristais-líquidos no interior de nanopartículas dispersas em água.

\subsection{5.}

\section{Nanopartículas núcleo-casca de copolímeros dibloco e surfactantes}

Sabe-se que os polímeros e surfactantes podem apresentar propriedades totalmente distintas das suas propriedades individuais quando são combinados em um mesmo sistema. Um caso marcante é o da mistura de polieletrólitos e surfactantes de cargas opostas em meio aquoso, que leva à complexação eletrostática entre as espécies, formando uma fase muito concentrada. Por ser muito concentrada em surfactantes, esta fase pode até apresentar estrutura líquido-cristalina. Alguns estudos recentes apresentam estratégias para evitar a separação de fases através de modificações na arquitetura do polímero utilizado ${ }^{19-21}$. Em um destes trabalhos, a estratégia consistiu em utilizar copolímeros dibloco, que possuem um bloco aniônico e outro bloco neutro e hidrofílico para se complexarem eletrostaticamente com surfactantes catiônicos ${ }^{20}$. Este procedimento já havia sido empregado anteriormente em estudos com outro enfoque, os quais demonstraram que a estrutura formada se tratava de uma nanopartícula do tipo núcleo-casca ${ }^{22,23}$. Os autores comprovaram por técnicas de espalhamento que a estrutura do complexo pode ser definida como uma partícula que possuiu um núcleo formado por uma alta concentração de micelas catiônicas que são neutralizadas e interconectadas pelos blocos aniônicos do copolímero. Já os blocos neutros formam uma casca externa, hidrofílica e difusa que mantem as partículas estáveis em meio aquoso ${ }^{23}$, como é ilustrado na figura 7 . 


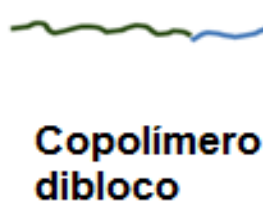

Copolim

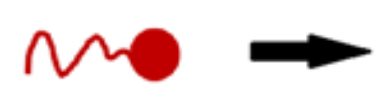

Surfactante

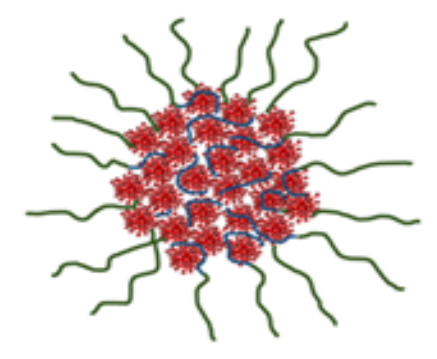

Nanoparticula núcleo-casca

Figura 7: Formação e estrutura das nanopartículas núcleo-casca. Adaptado da referência20

Recentemente, foi demonstrado que o núcleo desta nanopartícula pode apresentar estrutura líquido-cristalina devido à alta concentração das micelas ${ }^{20}$. Desta forma, podemos afirmar que este sistema consiste de uma dispersão de uma fase líquido-cristalina que está localizada dentro dos núcleos das diferentes nanopartículas. Devido à baixa viscosidade na concentração de interesse e à presença de núcleos localmente concentrados em micelas que podem dissolver substâncias hidrofóbicas, este sistema pode apresentar um grande potencial para incorporar estas substâncias e em seguida realizar sua liberação ou deposição.

\subsection{6.}

\section{Proposta de formulação}

Com base nas características das nanopartículas núcleo-casca formada por copolímeros dibloco e surfactantes descritas na seção anterior, este trabalho propõe uma nova formulação com propriedades que atendem aos requisitos para um produto inovador e efetivo de proteção solar para cabelos.

Dentre as propriedades necessárias, destaca-se a necessidade de apresentar uma substância bloqueadora de radiação UVB, para evitar a degradação e perda de proteína dos cabelos expostos ao sol. Sabe-se que os produtos presentes no mercado (voltados para a pele, em sua maioria) se apresentam na forma de cremes ou emulsões devido ao fato das moléculas de filtro solar serem hidrofóbicas. Este tipo de apresentação não 
é adequado para uso nos cabelos, devido à sua alta viscosidade que dificulta a aplicação uniforme e também ao aspecto final do cabelo (na linguagem popular, um aspecto oleoso). Uma formulação com base aquosa e de baixa viscosidade permitiria a aplicação por spray, o que facilitaria a uniformização do produto e sua secagem. Também é necessário que o sistema apresente alta estabilidade para garantir que o produto possua um longo tempo de prateleira, postergando o seu prazo de validade. Esperase que este produto seja mais usado quando os consumidores vão a piscinas ou praias, onde ocorre maior exposição ao sol. Por isso, é desejável também que o produto seja a prova d'água. Finalmente, é recomendável que o produto forneça ao cabelo um aspecto agradável ao toque, como o de um condicionador sem enxágue.

Através do emprego das nanopartículas núcleo-casca em meio aquoso, propõe-se incorporar um filtro solar orgânico no núcleo hidrofóbico de micelas. As dispersões de nanopartículas devem ser preparadas em uma faixa de concentração em que o sistema apresente baixa viscosidade podendo ser aplicado como spray. Entretanto, devido à alta concentração local de micelas no núcleo, espera-se garantir um alto grau de incorporação do filtro solar. Por sua vez, os grupos neutros hidrofílicos que formam a casca das nanopartículas devem garantir alta estabilidade em meio aquoso, além de proporcionar o ancoramento das nanopartículas em superfícies hidrofílicas após a secagem, garantindo assim uma boa deposição principalmente nos fios mais danificados e a propriedade de prova d'água ${ }^{24}$. A presença do surfactante catiônico cloreto de hexadeciltrimetilamônio, já utilizado amplamente em produtos condicionadores de cabelos, deve garantir também uma melhor deposição e um aspecto mais agradável ao toque, por neutralizar as cargas negativas das cutículas, diminuindo assim a repulsão eletrostática que causa o popularmente chamado frizz. 
2.

\section{OBJETIVOS}

O presente trabalho tem como objetivo a obtenção e caracterização de uma formulação de protetor solar para cabelos obtida a partir de nanopartículas formadas a base de copolímeros dibloco e surfactante catiônico. Isto será realizado através dos seguintes passos metodológicos:

- Incorporação de uma substância hidrofóbica, bloqueadora de radiação UVB, nas nanopartículas núcleo-casca;

- Verificação dos efeitos da variação nos comprimentos dos blocos do copolímero sobre as propriedades de incorporação e estrutura das nanopartículas;

- Caracterização estrutural das nanopartículas e investigação do efeito das substâncias hidrofóbicas incorporadas através de técnicas de espalhamento;

- Otimização do sistema e verificação do seu potencial como formulação de um produto de proteção solar para cabelos. 


\section{3.}

\section{EXPERIMENTAL}

\section{1.}

\section{Reagentes}

Polímeros

Os copolímeros dibloco poli(óxido de etileno)-b-poli(ácido metacrílico), PEOm-b-PMAAn, utilizados no preparo das nanopartículas foram adquiridos da Polymer Source, em três diferentes graus de

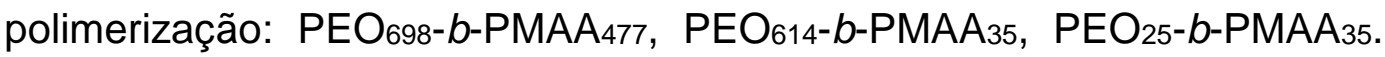
Inicialmente os copolímeros foram adicionados à água e afim de facilitar a dissolução dos copolímeros (que acidificam o meio, por ter o valor de pka igual a 4,5), a mistura foi mantida sob agitação e foi gotejada uma solução de hidróxido de sódio $(\mathrm{NaOH}) \quad 0,1 \mathrm{~mol} \mathrm{~L}^{-1}$ até a dissolução completa dos copolímeros, que ocorria em pH em torno de 7.

Surfactante

O surfactante utilizado foi o cloreto de hexadeciltrimetilamônio (CTAC), na forma de solução aquosa $20 \% \mathrm{~m} / \mathrm{m}$ de Dehyquart® A-CA, fornecido pela BASF.

\section{Filtro solar}

A molécula de filtro solar utilizada foi o octilmetoxicinamato, um filtro orgânico de radiação UVB, conhecido comercialmente como Uvinulß MC 80 , fornecido pela BASF.

\section{2.}

\section{Preparação das nanopartículas núcleo-casca}

Para o preparo das nanopartículas, a solução aquosa de $\mathrm{PEO}_{\mathrm{m}-}-b$ $\mathrm{PMAA}_{n}$ (já com o $\mathrm{pH}$ em torno de 7 pela adição de $\mathrm{NaOH}$ ) foi misturada com a solução aquosa do CTAC, na concentração adequada para garantir uma proporção estequiométrica com os grupos de ácido metacrílico. Desta 
forma, cada monômero aniônico deve neutralizar uma molécula de surfactante catiônico. Após agitação magnética para garantir a homogeneização, as nanopartículas núcleo-casca se formam espontaneamente através de complexação eletrostática. Nestas amostras, a concentração final de nanopartículas em água (complexo polímerosurfactante) era de $2,5 \%(\mathrm{~m} / \mathrm{m})$.

\section{3.}

Incorporação das moléculas hidrofóbicas de filtro solar.

A amostra de nanopartículas a 2,5\% $(\mathrm{m} / \mathrm{m})$ foi mantida sob agitação magnética, enquanto o óleo octilmetoxinamato foi adicionado gota-a-gota. A adição de cada gota só foi realizada após verificar que a gota anterior já havia sido incorporada e o sistema estava macroscopicamente homogêneo. No momento em que a gota adicionada não foi homogeneizada na amostra, foi determinada a incorporação máxima do filtro no sistema. Da mesma forma, foram preparadas amostras com diferentes concentrações do filtro solar, menores que a máxima, para posterior caracterização.

\section{4.}

Técnicas de caracterização

\subsection{1.}

\section{Espalhamento dinâmico de luz (DLS)}

A técnica de DLS, espalhamento de luz dinâmico, também chamada de espectroscopia de correlação de fótons, é baseada no fenômeno de espalhamento de luz. Ela pode dar informações de difusão e tamanho das partículas entre outras informações relacionadas à dinâmica do material. As medidas se baseiam em medições da intensidade de luz espalhada como uma função do tempo. Graças ao movimento browniano das partículas espalhadoras (possuem uma trajetória aleatória), ocorrem 
flutuações da intensidade da luz espalhada, que podem fornecer o coeficiente de difusão e informações de dimensão através de funções estatísticas e de correlação ${ }^{25}$.

Quando se mede a intensidade de luz espalhada por partículas que seguem o movimento Browniano, é possível observar uma oscilação no valor de intensidade ao longo do tempo. Quanto menores as partículas, mais rapidamente elas se movimentam e por isso a frequência de oscilação também é maior. Através desta relação, pode-se obter informações da dinâmica e tamanho das partículas a partir dos registros de intensidade espalhada em função do tempo ${ }^{25}$.

As medidas de DLS foram realizadas na Central Analítica Padre Leopoldo Hainberger (CAPLH), na PUC-Rio, utilizando o equipamento Horiba modelo Nanopartica SZ-100 com laser de $10 \mathrm{~mW}$ como feixe incidente com comprimento de onda de $532 \mathrm{~nm}$. Todas as medidas foram feitas em triplicata a $25,0^{\circ} \mathrm{C}$, com duração de $120 \mathrm{~s}$, a um ângulo, $\theta$, de 90 ${ }^{\circ}$ e/ou $173^{\circ}$. Foi utilizada uma cubeta de poliestireno de quatro faces polidas e caminho óptico igual a $1,00 \mathrm{~cm}$.

Para o preparo das amostras, cada cubeta foi lavada diversas vezes com água Milli- $\mathrm{Q}{ }^{\circledR}$ e mantida fechada todo o tempo, a fim de evitar o contato com partículas de poeira que poderiam contaminar a amostra. Um volume de $80 \mu \mathrm{L}$ de amostra de nanopartículas núcleo-casca a 2,5\% $(\mathrm{m} / \mathrm{m})$, contendo ou não o filtro solar, foi adicionada à cubeta. Nos casos em que houve formação de precipitado, este não foi incluído durante a adição. Em seguida, foi adicionada água Milli- $\mathrm{Q} \AA$ até completar um volume de 2,0 $\mathrm{mL}$ e atingir a concentração $0,1 \%(\mathrm{~m} / \mathrm{m})$ de nanopartículas. Algumas amostras foram reanalisadas após o período de sessenta dias, para verificar o efeito do tempo na sua estabilidade.

\subsection{2.}

\section{Espalhamento de raios $\mathrm{X}$ a baixos ângulos (SAXS)}

Através da técnica de SAXS é possível determinar a forma, o tamanho e a estrutura de partículas em escala nanométrica e que não 
podem ser determinados por outras técnicas, como difração de raios $\mathrm{Xe}$ espalhamento de luz dinâmico.

Os dados de SAXS são apresentados em gráficos de intensidade, I, em função do vetor de espalhamento, q, definido pela Equação 1 , sendo $\lambda$ o comprimento de onda e $\theta$ o ângulo entre a onda incidente e a espalhada em uma dada posição do detector ${ }^{26}$.

$$
q=\frac{4 \pi}{\lambda} \operatorname{sen} \theta \quad \text { Equação } 1
$$

Para estruturas com ordem a longa distância, como cristais e fases líquido-cristalinas, com conjunto de planos paralelos separados por uma distância d, as interferências construtivas de um feixe incidente a um dado ângulo $\theta$ são descritas pela lei de Bragg ${ }^{26}$.

\section{$n \lambda=2 d \operatorname{sen} \theta \quad$ Equação 2}

A estrutura das fases líquido-cristalinas é determinada através da posição dos picos de difração. Quanto mais ordenado é o sistema, mais pronunciados e definidos são os picos de Bragg. A posição relativa entre os picos pode ser utilizada para identificar as fases líquido-cristalinas e obter o valor da distância interplanar, $d$, e até mesmo das dimensões da cela unitária.

Fases lamelares, por exemplo, são facilmente identificadas, porque as posições relativas dos picos de Bragg no eixo $\times(q)$ satisfazem a equação da seguinte maneira:

$$
q=\frac{n 2 \pi}{d}, \text { sendo } \quad \mathrm{n}=1,2,3 \ldots . \text { Equação } 3
$$

Já nas fases hexagonais os valores de n são: $\sqrt{1}, \sqrt{3}, \sqrt{4}, \sqrt{7}, \sqrt{9}$, $\sqrt{12}$ e na fase cúbica Pm3n, os valores de n são: $\sqrt{1}, \sqrt{2}, \sqrt{3}, \sqrt{4}, \sqrt{5} 26$.

As medidas de SAXS foram realizadas na linha SAXS1 do Laboratório Nacional de Luz Síncrotron, LNLS. As amostras foram posicionadas em uma cela com janela de mica, sob temperatura controlada 
a $25,0{ }^{\circ} \mathrm{C}$. Os experimentos foram realizados com um feixe incidente de comprimento de onda de $1,488 \AA$ e com tempo de exposição de 120 segundos. A faixa de $q$ obtida foi de 0,1 e $4,8 \mathrm{~nm}^{-1}$ ao utilizar a distância entre porta-amostras e detector de $0,5 \mathrm{~m}$. As imagens obtidas foram integradas com o software Fit2D, subtraindo a inomogeneidade do sinal e o espalhamento do branco (água pura) para obter as curvas de intensidade em função do vetor de espalhamento.

\section{5.}

Verificação do potencial da amostra como formulação de um produto de proteção solar para cabelos.

\subsection{1.}

\section{Espectroscopia na região Ultravioleta e Visível}

A espectrofotometria ultravioleta e visível é um dos métodos analíticos mais usados nas determinações analíticas em diversas áreas, e é aplicada tanto para determinação de compostos inorgânicos como para compostos orgânicos.

A absorção da radiação visível e ultravioleta depende, em primeiro lugar, do número e do arranjo dos elétrons nas moléculas ou íons absorventes. Como consequência, o pico de absorção pode ser correlacionado com o tipo de ligação que existe na espécie que está sendo estudada. É uma ferramenta valiosa para a identificação de grupos funcionais na molécula, extremamente útil para a determinação quantitativa de compostos contendo grupos absorventes ou cromóforos.

Quando uma radiação contínua atravessa um material, uma parte da radiação pode ser absorvida. Se isso ocorrer, a radiação residual, ao atravessar um prisma, produzirá um espectro de absorção. Como resultado da absorção de energia, átomos ou moléculas passam de um estado de energia mais baixa (inicial ou estado fundamental) para um estado de energia maior (estado excitado). A radiação eletromagnética absorvida tem energia exatamente igual à diferença de energia entre os estados excitado e fundamental ${ }^{27}$. 
No caso das espectroscopias ultravioleta e visível, as transições que resultam em absorção de radiação eletromagnética nessa região do espectro ocorrem entre níveis de energia eletrônicos. Quando uma molécula absorve energia, um elétron é promovido de um orbital ocupado para um orbital desocupado de maior energia potencial ${ }^{27}$.

Quanto maior for o número de moléculas capazes de absorver luz de um certo comprimento de onda, maior será a extensão dessa absorção. Além disso, quanto maior for a eficiência que uma molécula tem de absorver luz de um certo comprimento de onda, maior será a extensão dessa absorção. Com base nessas ideias iniciais, pode-se formular a seguinte expressão empírica, chamada de Lei de Beer-Lambert ${ }^{27}$.

\section{$A=\log \frac{I o}{I}=\varepsilon c l$ para um certo comprimento de onda}

\section{Equação 4}

A = absorbância

$l_{o}=$ intensidade de luz incidindo na cela de amostra

I - intensidade de luz saindo da cela de amostra

$c=$ concentração molar do soluto

$I=$ caminho óptico $(\mathrm{cm})$

$\varepsilon=$ absortividade molar

Para avaliar a quantidade de octilmetoxicinamato nas amostras, espectros de ultravioleta foram obtidos no Laboratório de Macromoléculas e Nanopartículas (M\&N Lab) da PUC-Rio através de um espectrofotômetro Boeco modelo S-220. As amostras foram colocadas em cubeta de quartzo com quatro faces polidas e caminho óptico igual a 1,0 cm. A subtração do branco foi feita com uma amostra de água pura nas mesmas condições experimentais.

A mesma técnica também foi usada para avaliar a deposição da amostra sobre superfícies hidrofílicas. Para isso, uma placa de quartzo foi deixada de molho em água régia (solução de ácido nítrico e clorídrico concentrados e em proporção de 1:3) a fim de garantir a hidrofilicidade do substrato. Em seguida, a placa foi enxaguada com água Milli- ${ }^{\circledR}$ e seca, 
para então receber um jato de spray de uma amostra de formulação. Após secar novamente, esta placa foi colocada no mesmo espectrofotômetro para se obter um espectro de absorção. A subtração do branco foi feita com a placa limpa nas mesmas condições experimentais. $O$ experimento foi repetido após a placa, contendo a formulação em sua superfície, ser deixada de molho em água por 30 minutos, para avaliar se a formulação era a prova d'água.

\subsection{2.}

\section{Espectroscopia de absorção na região do Infravermelho}

A espectroscopia no infravermelho (espectroscopia IV) é um tipo de espectroscopia de absorção que usa a região do infravermelho do espectro eletromagnético. Como as demais técnicas espectroscópicas, ela pode ser usada para identificar um composto ou investigar a composição de uma amostra. ${ }^{27}$ Quase todos os compostos que tenham ligações covalentes, sejam orgânicos ou inorgânicos, absorvem várias frequências de radiação eletromagnética na região do infravermelho do espectro eletromagnético.

Essa região envolve comprimentos de onda maiores do que aqueles associados à luz visível, que vão de aproximadamente 400 a 800 nm, mas menores do que aqueles associados a micro-ondas, que são maiores que $1 \mathrm{~mm}$. Neste caso, a região de interesse é a região vibracional do infravermelho, que inclui radiação com comprimentos de ondas entre 2,5 $\mu \mathrm{m}$ e $25 \mu \mathrm{m}^{27}$.

Vários dos equipamentos de espectroscopia possuem acessórios que auxiliam as análises de amostras sólidas e líquidas, como por exemplo o acessório para espectroscopia de refletância total atenuada (ATR) por diamante. Quando uma amostra é colocada em contato com o sensor de ATR por diamante, uma pequena quantidade de radiação infravermelha passa através do diamante em direção a amostra e é totalmente refletida em sua superfície interna, dessa forma o feixe de luz penetra numa camada fina da superfície da amostra absorvente e sofrerá perda de energia nos comprimentos de onda característicos em que o material absorve. 
Neste trabalho, os espectros de infravermelho de fios de cabelo foram obtidos em um espectrofotômetro de absorção na região do infravermelho afastado, modelo 100 FT-IR, da Perkin-Elmer. A amostragem foi feita com o auxílio do acessório de refletância total atenuada (ATR) por diamante. Os dados foram coletados na região de 4000-650 $\mathrm{cm}^{-1}$. Algumas bandas características de aminoácidos presentes no cabelo foram acompanhadas para verificar a ocorrência de degradação por exposição à radiação ultravioleta. As análises foram realizadas no Laboratório de Biocombustíveis (LABIO), do Departamento de Química da PUC-Rio.

\subsection{3.}

\section{Exposição de cabelos a radiação}

Para todos os experimentos envolvendo análise de fios de cabelo, foram utilizadas mechas de uma mesma amostra de cabelos da cor preta, sem tratamento químico prévio (como tintura, descoloração, alisamento, etc.). A amostra foi doada voluntariamente, por uma pessoa do sexo feminino e com 27 anos de idade. Foram selecionadas doze mechas que continham exatamente nove fios cada. Para remover possíveis resíduos deixados por produtos utilizados pela voluntária, todas as mechas foram previamente lavadas com uma solução com $0,01 \mathrm{~mol}^{-\mathrm{L}^{-1}}$ de lauril sulfato de sódio, enxaguadas com água em abundância, e deixadas para secar por 24 horas a temperatura ambiente. Algumas destas mechas foram borrifadas com a formulação e aguardou-se o intervalo de 10 minutos até o início da próxima etapa.

Para verificar o efeito da radiação UVB em cabelos com e sem a aplicação da formulação, este trabalho envolveu também a construção de uma câmara de radiação. Para isso, foi feita uma caixa de madeira com altura de $20 \mathrm{~cm}$, largura de $25 \mathrm{~cm}$ e $40 \mathrm{~cm}$ de extensão, na qual foi acoplado o filamento de uma lâmpada de vapor de mercúrio com $125 \mathrm{~W}$, cujo bulbo com filtro UVB e UVC foi retirado. Também foi instalada uma ventoinha para remover o gás ozônio possivelmente formado pelo filamento. A câmara foi sempre utilizada dentro de capela e a Figura 7 apresenta sua foto. 


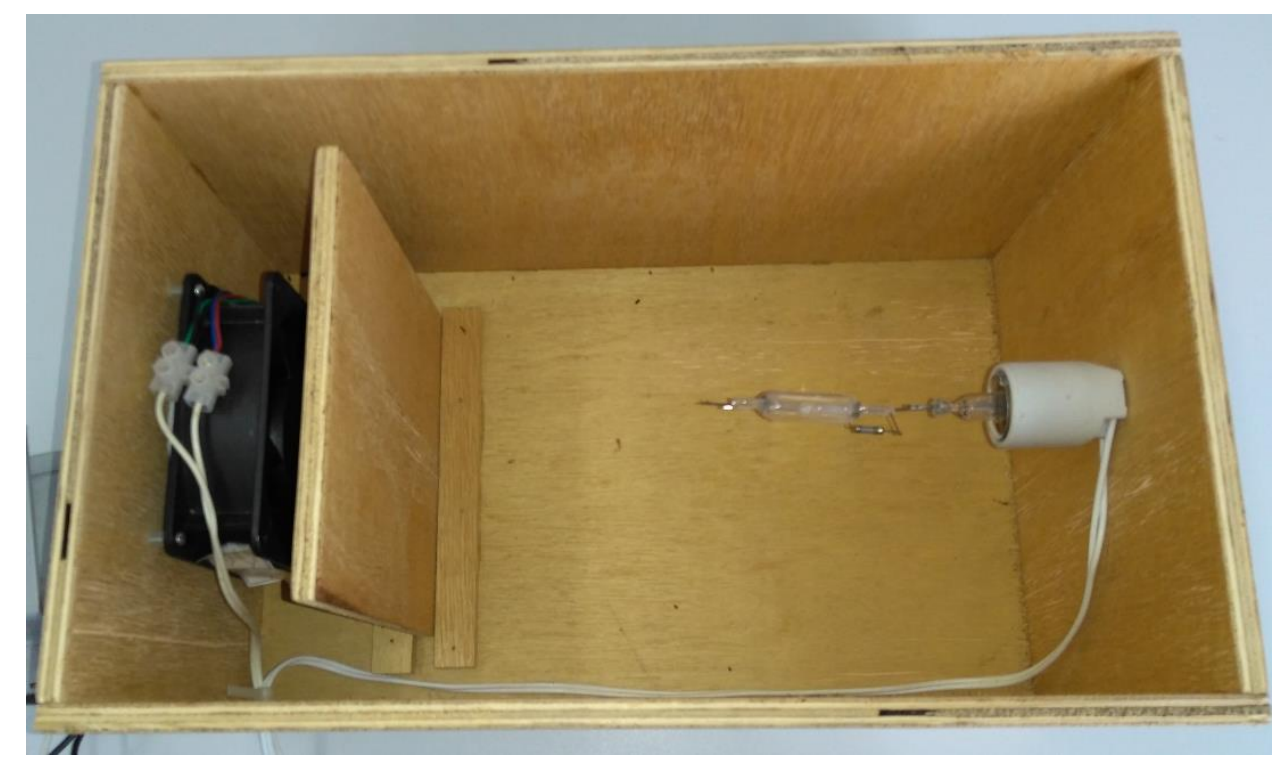

Figura 8: Câmara de radiação ultravioleta.

Para garantir que o filamento emita radiação na região do UVB e verificar onde se encontram todas as suas linhas de emissão, foi determinado o espectro de emissão da lâmpada. Para isso, foi realizada uma medida em um espectrofluorímetro fabricado pela Photon Technology Internacional, modelo QM1 equipado com a lâmpada modelo LPS-220, fotomultiplicador modelo 810 e motor modelo MD-5020, do Laboratório de Espectroscopia de Biomoléculas (Departamento de Física - PUC-Rio). Para isso, a lâmpada foi acesa dentro do espectrofluorímetro e posicionada de modo a irradiar uma amostra de dispersão de nanopartículas de poliestireno. O espalhamento da radiação por esta amostra foi medido a um ângulo de $90^{\circ}$. Utilizando o espectro de espalhamento medido foi obtido o espectro de emissão da lâmpada, baseando-se na relação de que a intensidade de emissão deve ser diretamente proporcional à intensidade espalhada multiplicada por $\lambda^{4}$ (de acordo com a equação de Rayleigh). $\mathrm{O}$ espectro de emissão mostrado pela Figura 8, confirma a presença de linhas de emissão na região do UVB (294, 300 e principalmente em 311 nm), mas também evidenciou a presença de outras linhas de emissão nas regiões de UVC, UVA e Visível, o que torna o aparato ainda mais interessante para simular a radiação solar. 


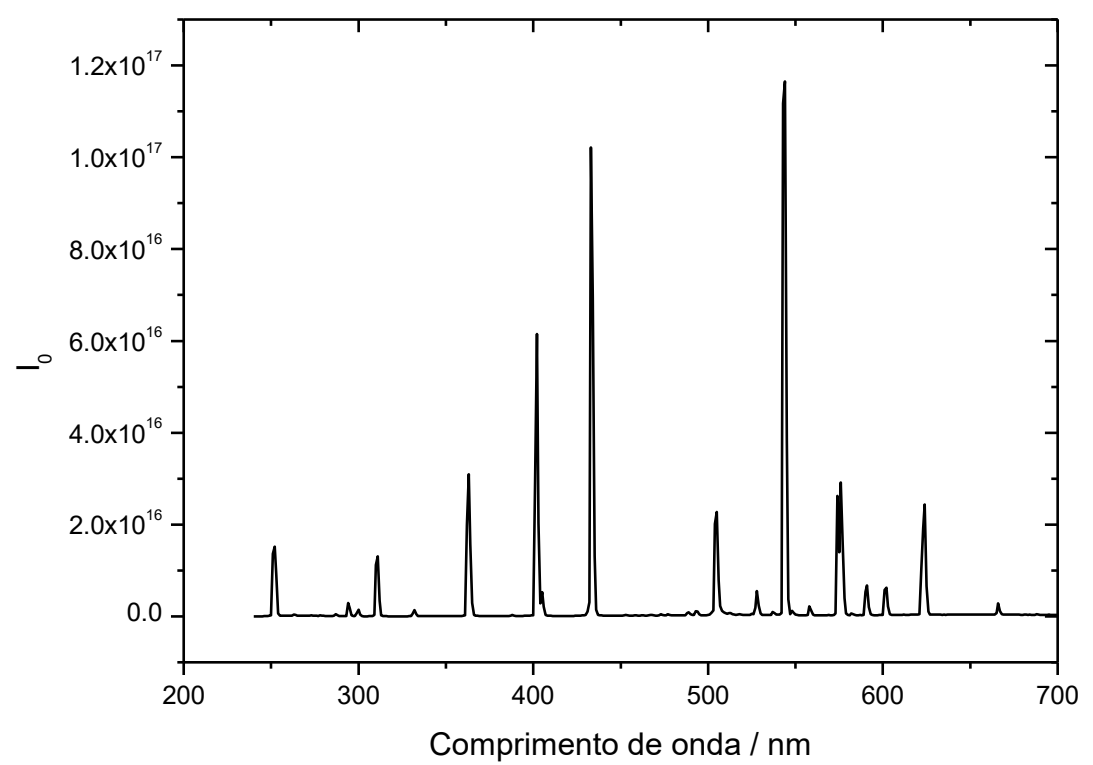

Figura 9: Espectro de emissão da fonte utilizada na câmara de radiação.

Primeiramente as mechas foram analisadas por espectroscopia na região do infravermelho (conforme descrito na seção seguinte) sem qualquer tratamento além da lavagem mencionada anteriormente. Em seguida, foi realizada um tratamento diferente para cada três mechas, para garantir que as análises fossem feitas em triplicata. O Tratamento 1 consistiu na exposição à radiação na câmera por 6 horas. $O$ Tratamento 2 consistiu na aplicação da formulação contendo filtro solar, secagem parcial por 15 minutos e exposição à radiação na câmera por 6 horas. $O$ Tratamento 3 consistiu apenas na aplicação da formulação e o Tratamento 4 consistiu em manter as mechas em repouso, sem aplicação de formulação e sem exposição à radiação. Ao final dos tratamentos, as mechas foram analisadas novamente, a fim de observar alterações principais bandas que caracterizam a degradação capilar. 


\section{RESULTADOS}

\section{1.}

\section{Incorporação do octilmetoxicinamato nas nanopartículas núcleo- casca}

A Tabela 2 apresenta os valores de concentração máxima de octilmetoxicinamato incorporado nas nanopartículas núcleo-casca formada pelos complexos de três copolímeros diferentes. É possível observar que o complexo $\mathrm{PEO}_{698}-b-\mathrm{PMAA}_{477}-\mathrm{CTAC}$ apresenta uma capacidade de incorporação de moléculas hidrofóbicas muito superior, seguido do complexo $\mathrm{PEO}_{614-} b-\mathrm{PMAA}_{35}$, e finalmente do complexo $\mathrm{PEO}_{25}-b-\mathrm{PMAA}_{35}$ CTAC. Esta ordem indica que, quanto mais longo é o bloco de PMAA, maior é a incorporação de moléculas hidrofóbicas, este resultado é possível pois o bloco de PMAA é o responsável pela complexação com o surfactante catiônico e consequentemente pela formação do núcleo de micelas na nanopartícula núcleo-casca. Também foi possível observar que para garantir a incorporação do octilmetoxicinamato é necessária uma adição gradativa do mesmo. Se a adição for realizada de uma vez só, são formadas duas fases. Para finalidades de comparação, este experimento foi realizado também com uma solução de $2,5 \%$ de CTAC ao invés do complexo, porém não houve incorporação significativa do óleo.

Tabela 2: Porcentagem de incorporação máxima do filtro solar hidrofóbico nas nanopartículas núcleo-casca formadas pelos diferentes complexos.

\begin{tabular}{|c|c|c|}
\hline & $\begin{array}{c}\text { PEO }_{698}-b- \\
\text { PMAA }_{477-C T A C}\end{array}$ & $\begin{array}{c}\text { PEO }_{614-} b- \\
\text { PMAA }_{35-C T A C}\end{array}$ \\
\hline
\end{tabular}

$\begin{array}{cccc}\begin{array}{c}\text { Incorporação } \\ (\% \mathrm{~m} / \mathrm{m})\end{array} & 4,0 \% & 0,3 \% & <0,3 \%\end{array}$




\section{2.}

\section{Caracterização}

\subsection{1.}

\section{Resultados de DLS}

As nanopartículas de todos os complexos apresentam diâmetro hidrodinâmico na ordem de dezenas a centenas de nanômetros (Tabela 3). Ao comparar os complexos PEO698-b-PMAA477-CTAC e PEO614-b-PMAA35CTAC, observa-se que as nanopartículas do primeiro apresentam diâmetro hidrodinâmico em torno de cinco vezes maior que as do segundo. Como o comprimento do bloco de PEO é parecido para os dois sistemas, podemos afirmar que o complexo com bloco iônico mais longo deve formar nanopartículas com um núcleo maior, já que cada bloco deve neutralizar e se envolver em um número maior de micelas. Mas ao comparar os complexos PEO $614-b-\mathrm{PMAA}_{35}-\mathrm{CTAC}$ e $\mathrm{PEO}_{25}-b_{-} \mathrm{PMAA}_{35}-\mathrm{CTAC}$ que possuem blocos iônicos iguais, observa-se que as nanopartículas do segundo possuem diâmetro hidrodinâmico em torno de duas vezes maior

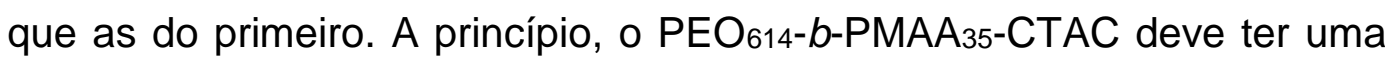
casca hidrofílica mais espessa, porém, os longos blocos hidrofílicos de PEO614 devem dispersar melhor as nanopartículas, que por sua vez apresentam um tamanho menor do que no $\mathrm{PEO}_{25}-b-\mathrm{PMAA}_{35}-\mathrm{CTAC}$.

Os resultados de DLS das nanopartículas dos complexos $\mathrm{PEO}_{698}-b-$ PMAA477-CTAC, PEO $614-b-$ PMAA $_{35}-$ CTAC e PEO $25-b-$ PMAA $_{35}-$ CTAC com ou sem octilmetoxicinamato, mostram que as moléculas hidrofóbicas do filtro solar não causam alteração significativa do diâmetro hidrodinâmico em amostras recém-preparadas, como pode ser observado na Figura 9 e na Tabela 3. Poderia se esperar que a incorporação do óleo no núcleo causasse um aumento do mesmo, mas como isso não foi observado, é possível que as moléculas hidrofóbicas causem uma maior organização das micelas no núcleo. Para comprovar esta hipótese, análises de SAXS foram realizadas conforme será descrito na próxima sessão. 


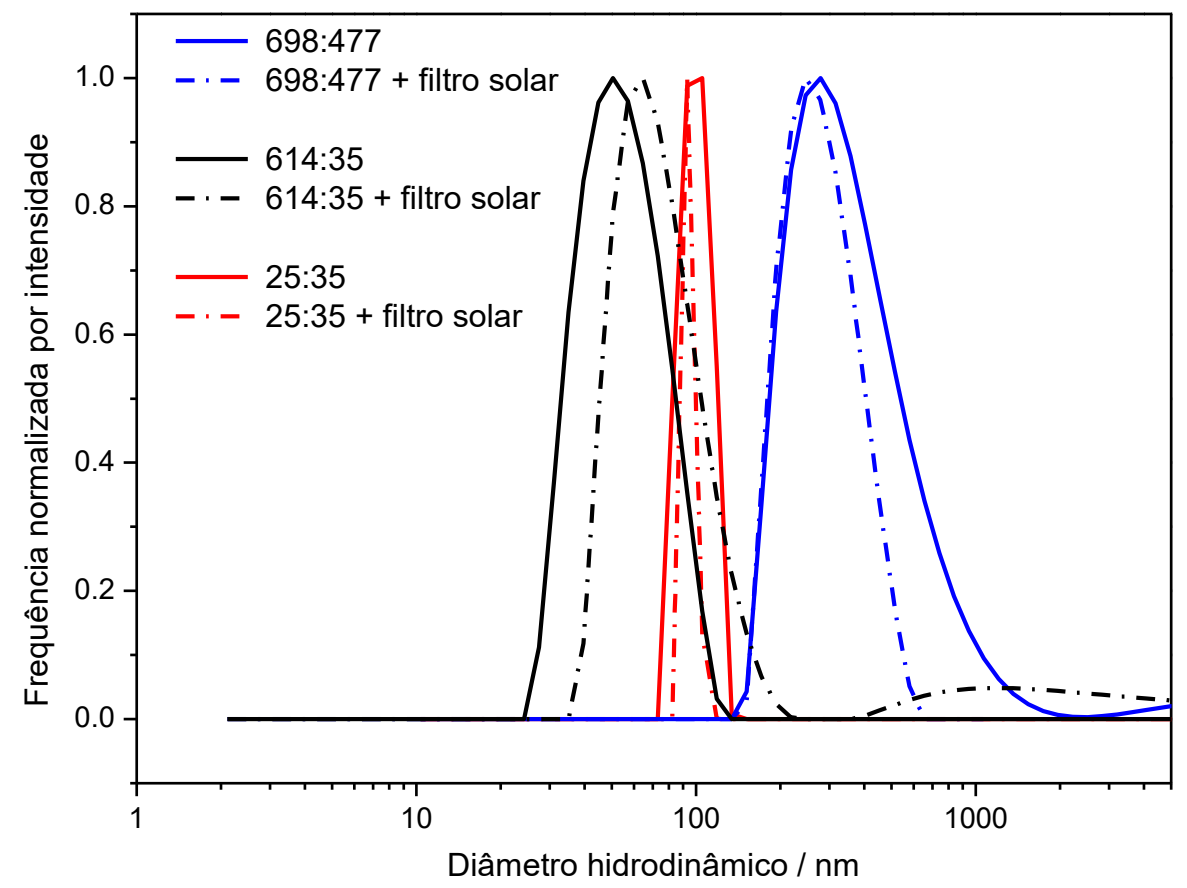

Figura 10: Curvas de distribuição de diâmetro hidrodinâmico de amostras de diferentes complexos em meio aquoso, na ausência (linha sólida) ou na presença da concentração máxima de octilmetoxicinamato (linha tracejada). Os números indicam as unidades monoméricas do bloco de PEO e PMAA (m:n), respectivamente, dos copolímeros que formam cada um dos complexos.

Após 2 meses, foi realizada a repetição das medidas de dois dos sistemas estudados e os valores de diâmetro hidrodinâmico médios estão apresentados na Tabela 3. Estes resultados mostram que as nanopartículas de PEO698-b-PMAA477-CTAC contendo a concentração máxima de octilmetoxicinamato não apresentam uma variação considerável de tamanho durante este intervalo de tempo. Estes valores foram acompanhados por até 6 meses e continuaram não apresentando alterações significativas. Por outro lado, as nanopartículas do $\mathrm{PEO}_{25}-b$ PMAA $_{35}$-CTAC apresentam um aumento significativo de tamanho após 2 meses, principalmente as que contém octilmetoxicinamato incorporado em seu interior, mostrando que não são tão estáveis quanto o sistema anterior, apesar de apresentarem tamanho menor. A superior estabilidade das

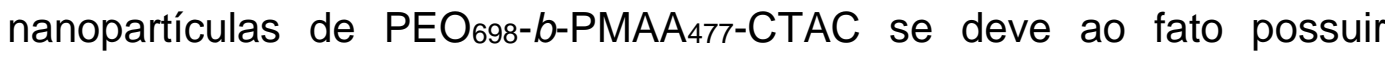
cadeias mais longas de PEO, que é o bloco hidrofílico que estabiliza as nanopartículas em meio aquoso. No caso do complexo $\mathrm{PEO}_{25}-b-\mathrm{PMAA}_{35}$ CTAC, os blocos de PEO são muito curtos (apenas 25 unidades 
monoméricas) para manter as nanopartículas estáveis e evitar a coagulação das mesmas.

Tabela 3: Valores de diâmetro hidrodinâmico médio (Dh) de nanopartículas e os respectivos desviospadrão (DP) das tripilicatas obtidos por medidas de DLS de diferentes complexos, antes e após a adição da concentração máxima de filtro solar.

\begin{tabular}{|c|c|c|c|c|c|c|}
\hline \multirow{2}{*}{ Complexo } & \multirow[b]{2}{*}{$\begin{array}{c}\text { Ângulo } \\
\theta\end{array}$} & \multicolumn{2}{|c|}{$\begin{array}{c}\text { Recém- } \\
\text { preparada }\end{array}$} & \multicolumn{2}{|c|}{$\begin{array}{l}\text { Após } 2 \\
\text { meses }\end{array}$} & \multirow{2}{*}{$\begin{array}{c}\text { Variaçãc } \\
\text { relativa } \\
\text { com o } \\
\text { tempo } \\
(\%)\end{array}$} \\
\hline & & $\begin{array}{c}\mathrm{Dh}_{\mathrm{h}} \\
(\mathrm{nm})\end{array}$ & $\begin{array}{l}\mathrm{DP} \\
(\mathrm{nm})\end{array}$ & $\begin{array}{c}\mathrm{Dh}_{\mathrm{h}} \\
(\mathrm{nm})\end{array}$ & $\begin{array}{c}\mathrm{DP} \\
(\mathrm{nm})\end{array}$ & \\
\hline $\begin{array}{c}\text { PEO }_{698}-b-P^{-} \text {CTAA }_{477-} \\
\text { CTAC }\end{array}$ & $90^{\circ}$ & 251 & 8 & 238 & 2 & 4,9 \\
\hline $\begin{array}{c}\text { PEO }_{698-}-b-P{ }^{2} A_{477-} \\
\text { CTAC + } \\
\text { octilmetoxicinamato }\end{array}$ & $173^{\circ}$ & 266 & 6 & 243 & 33 & 8,8 \\
\hline $\begin{array}{c}\text { PEO }_{614-b-}-\mathrm{PMAA}_{35-} \\
\text { CTAC }\end{array}$ & $90^{\circ}$ & 51 & 6 & - & - & - \\
\hline $\begin{array}{c}\text { PEO }_{614-b-P M A A_{35-}} \\
\text { CTAC + } \\
\text { octilmetoxicinamato }\end{array}$ & $173^{\circ}$ & 52 & 3 & - & - & - \\
\hline $\begin{array}{c}\mathrm{PEO}_{25-}-b-\mathrm{PMAA}_{35-} \\
\text { CTAC }\end{array}$ & $90^{\circ}$ & 99 & 4 & 112 & 16 & 13 \\
\hline $\begin{array}{c}\mathrm{PEO}_{25-} b-\mathrm{PMAA}_{35-} \\
\text { CTAC + } \\
\text { octilmetoxicinamato }\end{array}$ & $90^{\circ}$ & 94 & 8 & 257 & 1 & 172 \\
\hline
\end{tabular}

\subsection{2.}

\section{Resultados de SAXS}

As Figuras 10, 11 e 12 apresentam as curvas de SAXS de amostras de nanopartículas dos diferentes complexos a 2,5\% $(\mathrm{m} / \mathrm{m})$ em meio aquoso, sem e com octilmetoxicinamato. Os picos observados nos gráficos dão informação do empacotamento das micelas no interior do núcleo das nanopartículas. Para a amostra do complexo PEO698-b-PMAA477-CTAC, a posição relativa dos picos indica que as micelas formam um fase líquidocristalina com estrutura cúbica $\mathrm{Pm} 3 \mathrm{n}$, antes mesmo da adição do octilmetoxicinamato. Este resultado é inédito, porque normalmente não há formação de cristal-líquido quando as nanopartículas são formadas na presença de contra-íons (como o cloreto do CTAC e o sódio proveniente da adição de $\mathrm{NaOH})^{20,23}$. Por outro lado, por se tratar de um surfactante 
com cadeia de 16 carbonos, na ausência dos contra-íons seria esperada a formação de uma fase hexagonal e não cúbica ${ }^{20}$. Portanto, este caso especial provavelmente se deve ao longo comprimento do bloco de PMAA477 que compõe o núcleo. O grande número de meros permite uma maior organização. Por outro lado, a presença dos contra-íons inibe parcialmente a organização e, por isso, não se forma a fase hexagonal, mas ela não é suficiente para impedir a formação de fase cúbica.

Os gráficos das amostras dos complexos $\mathrm{PEO}_{614}-b_{-} \mathrm{PMAA}_{35}-\mathrm{CTAC}$ e $\mathrm{PEO}_{25}-b-\mathrm{PMAA}_{35}-\mathrm{CTAC}$ apresentam apenas um pico relativamente largo indicando um sistema isotrópico, porém na iminência de formar uma fase de cristal-líquido. A distância de correlação das micelas, ou seja, a distância entre os centros de duas micelas vizinhas, é de 4,7 - 4,8 nm o que indica que elas estão muito próximas, já que o diâmetro de uma micela de CTAC é de 4,6 nm ${ }^{28}$. Este resultado mostra que, quando o bloco de PMAA é curto (35 unidades), não há formação de fase cúbica Pm3n. Isto poderia ser esperado já que há menos micelas ligadas a um mesmo bloco, e provavelmente elas não são suficientes para promover um ordenamento a longo alcance e formar uma fase líquido-cristalina.

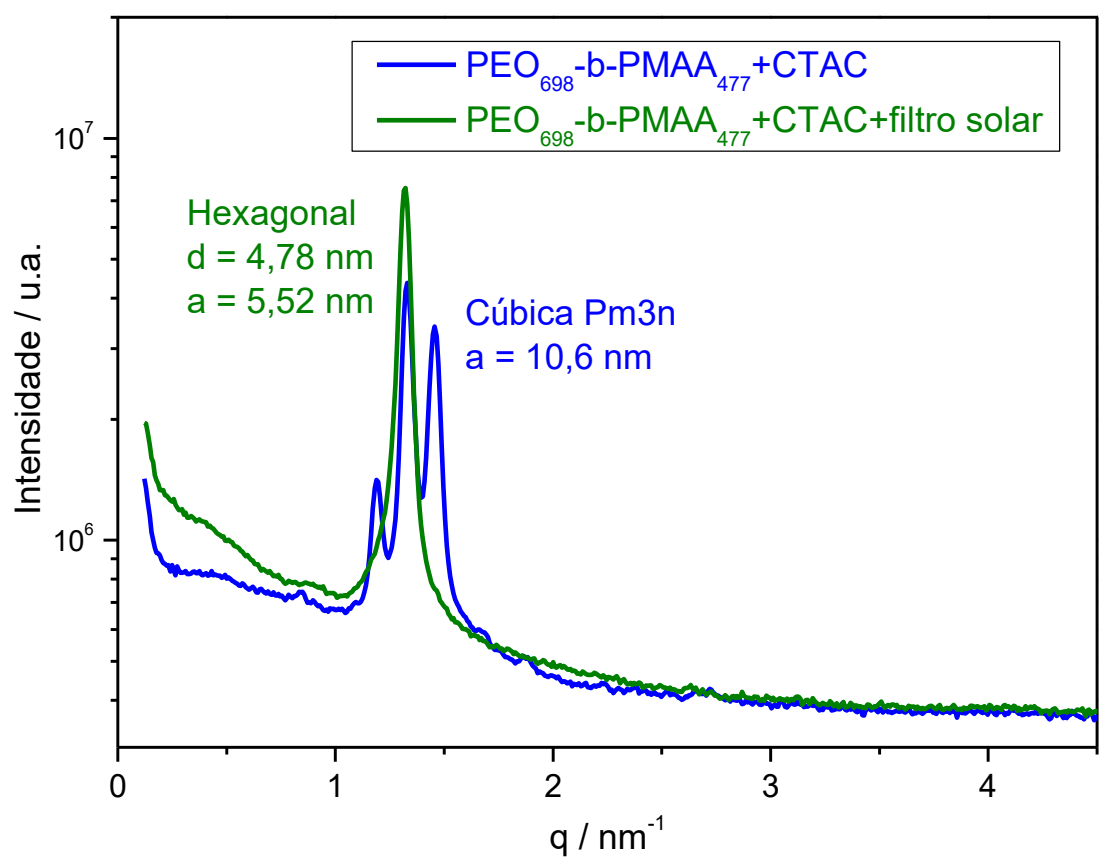

Figura 11: Resultados de SAXS para amostras de nanopartículas do complexo PEO698-b- 
PMAA477-CTAC em água, com e sem a adição de octilmetoxicinamato.

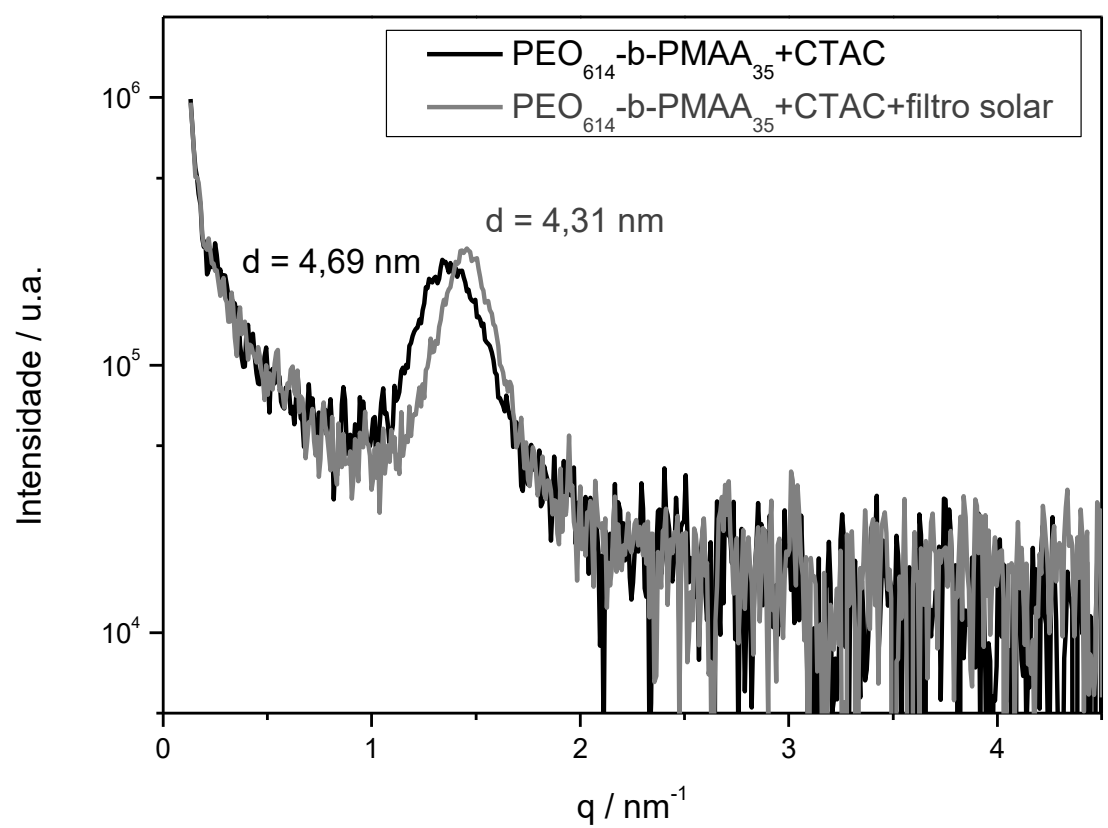

Figura 12: Resultados de SAXS para amostras de nanopartículas do complexo $P E O_{614-b-P M A A_{35-}}$ CTAC em água, com e sem a adição de octilmetoxicinamato.

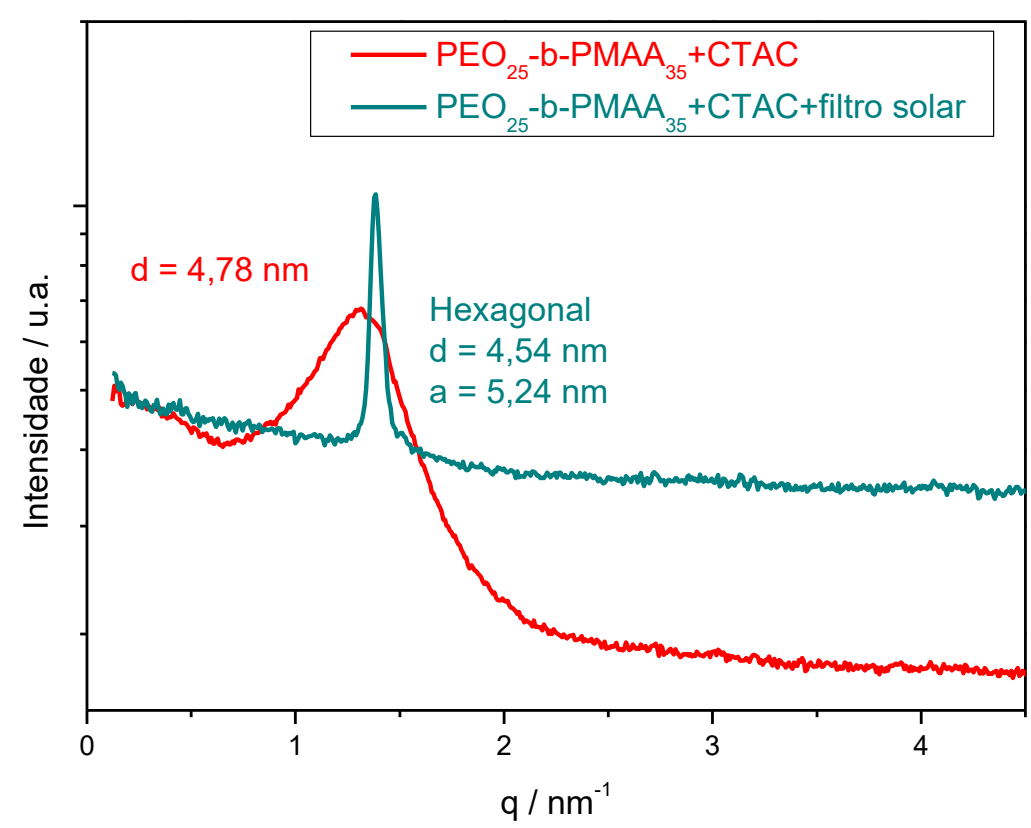

Figura 13: Resultados de SAXS para amostras de nanopartículas do complexo $P_{E O_{25}-b-P M A A_{35}-}$ CTAC em água, com e sem a adição de octilmetoxicinamato. 
Para todas as amostras, foi observada uma alteração na estruturação das micelas no interior do núcleo após a incorporação de octilmetoxicinamato nas nanopartículas. Nos casos dos complexos $\mathrm{PEO}_{698-}$ b-PMAA477-CTAC e PEO 25-b-PMAA35-CTAC há uma transição de fases, de forma que as micelas se reorganizam em uma estrutura hexagonal. Por outro lado, para o complexo PEO $_{614-b-P M A A_{35}-C T A C}$ não se observa uma transição de fases, provavelmente porque a quantidade de óleo que o complexo é capaz de incorporar é muito baixa e não é suficiente para promover uma transição. Porém a distância de correlação diminui, indicando uma maior aproximação das micelas. Isto indica que a adição de moléculas hidrofóbicas nas micelas leva a uma diminuição da curvatura e a um empacotamento mais efetivo das mesmas.

A transição para uma fase hexagonal significa uma redução na curvatura das micelas, conforme ilustrado pela Figura 13, e indica que as moléculas de octilmetoxicinamato atuam como cosurfactantes, intercalando-se com as moléculas de CTAC na micela. Isto pode ser compreendido ao observar a estrutura da molécula de octilmetoxicinamato: ela possui um formato relativamente alongado e caráter principalmente hidrofóbico, porém possui um grupo de maior densidade eletrônica em uma das extremidades, que é a metoxila $\left(-\mathrm{OCH}_{3}\right)$ ligada ao anel aromático. Este efeito já foi observado após a adição de $n$-álcoois a outros sistemas semelhantes de surfactante+polímero ${ }^{29,30}$. Neste mesmo trabalho, foi observado que quando moléculas mais hidrofóbicas, como p-xileno e ciclohexano, são apenas dissolvidas nas cadeias alquílicas dos surfactantes na micela, ocorre um aumento do parâmetro de cela, devido ao aumento do tamanho da micela e não há transição de fases ${ }^{29}$. No entanto, assim como os $n$-álcoois possuem uma cadeia hidrofóbica e uma extremidade de mais alta densidade eletrônica (devido à hidroxila), a molécula de octilmetoxicinamato possui uma região de maior densidade eletrônica devido à metoxila. Por isso, o filtro solar também é capaz de atuar como cosurfactante, posicionando-se entre as moléculas de surfactante e causando uma redução na curvatura da micela e a consequente transição para a fase hexagonal. Isto significa que a estrutura molecular do óleo adicionado é determinante para a estrutura de fase formada no núcleo e, 
portanto, o estudo com a incorporação de outros óleos pode levar a resultados diferentes. Vale mencionar que, na concentração escolhida, os picos de reflexão de Bragg da fase hexagonal - com exceção do primeiro - são de difícil observação devido à sua baixa intensidade e à presença de ruídos. Porém, ao analisar algumas amostras em concentração mais alta, eles se tornaram bem evidentes e a posição do primeiro pico não se alterou.

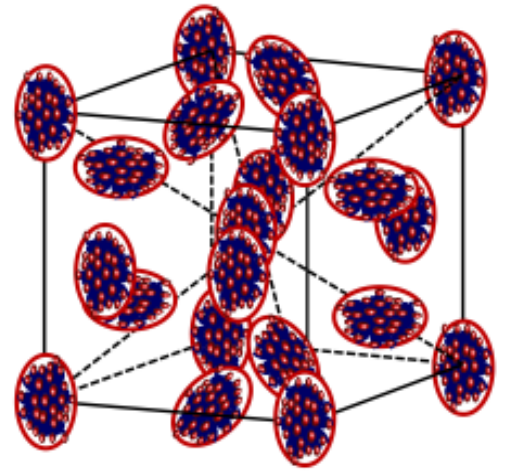

(a)

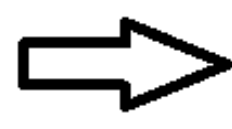

(b)

Figura 14: Representação da transição de fases que ocorre devido à reorganização das micelas no interior das nanopartículas núcleo-casca: (a) fase cúbica $P m 3 n$ antes da adição de octilmetoxicinamato, (b) fase hexagonal após a adição de octilmetoxicinamato. Adaptado da referência ${ }^{31}$.

Para o complexo PEO698-b-PMAA477, foram feitas análises de SAXS em diferentes concentrações, já que este complexo tem a capacidade de incorporar maiores quantidades do octilmetoxicinamato do que os demais complexos (conforme Tabela 2). Os resultados de SAXS apresentados na Figura 14 mostram que ao aumentar a concentração de filtro solar no complexo o valor do parâmetro de cela da fase hexagonal não se altera. Entretanto, os picos do gráfico sugerem que a formação de uma nova fase líquido cristalina, não identificada, ocorre em concentrações iguais e maiores que $1,3 \%(\mathrm{~m} / \mathrm{m})$. Esta fase poderia ser uma fase lamelar ou até mesmo uma fase reversa. Devido ao fato de que a distância de correlação obtida a partir do novo pico é muito baixa, não é esperado que ela corresponda à agregação das nanopartículas (o que formaria uma estrutura hierárquica). 


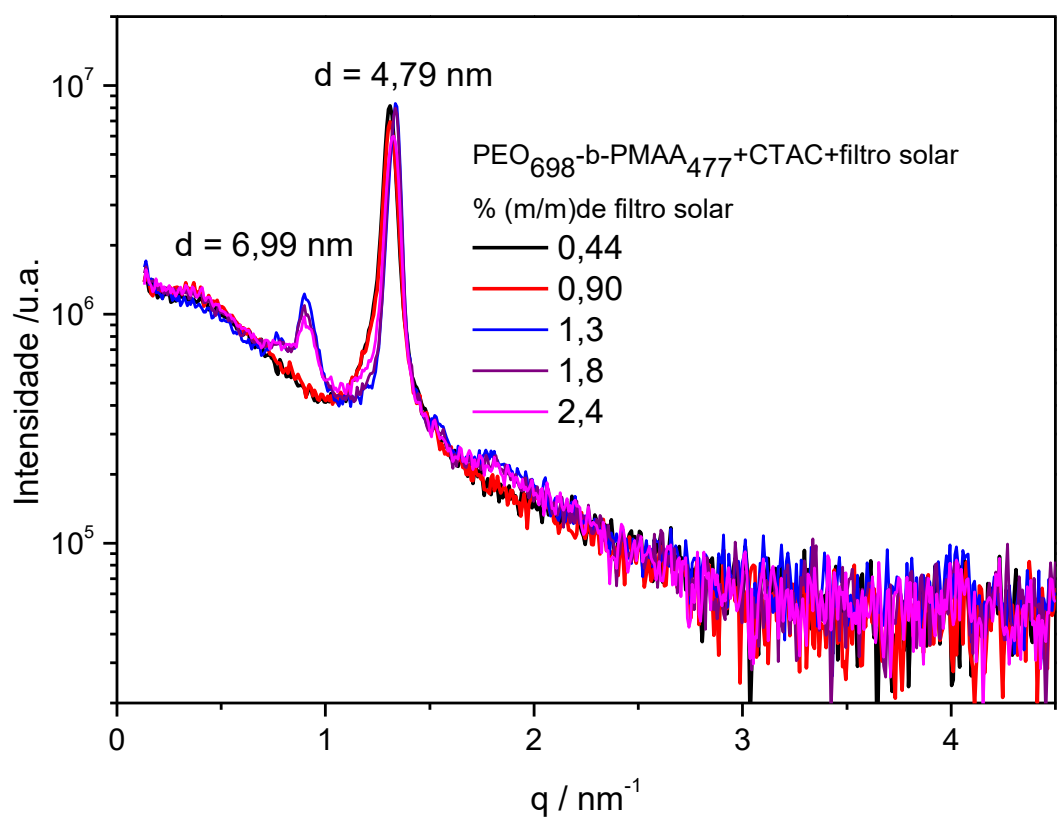

Figura 15: Resultados de SAXS para as amostras de nanopartículas do complexo PEO698-bPMAA477-CTAC em água, com octilmetoxicinamato a diferentes concentrações.

A repetição das análises das mesmas amostras após 2 meses, confirmou a reprodutibilidade e estabilidade da fase líquido-cristalina do núcleo, conforme exemplificado pelos dados da Figura 15.

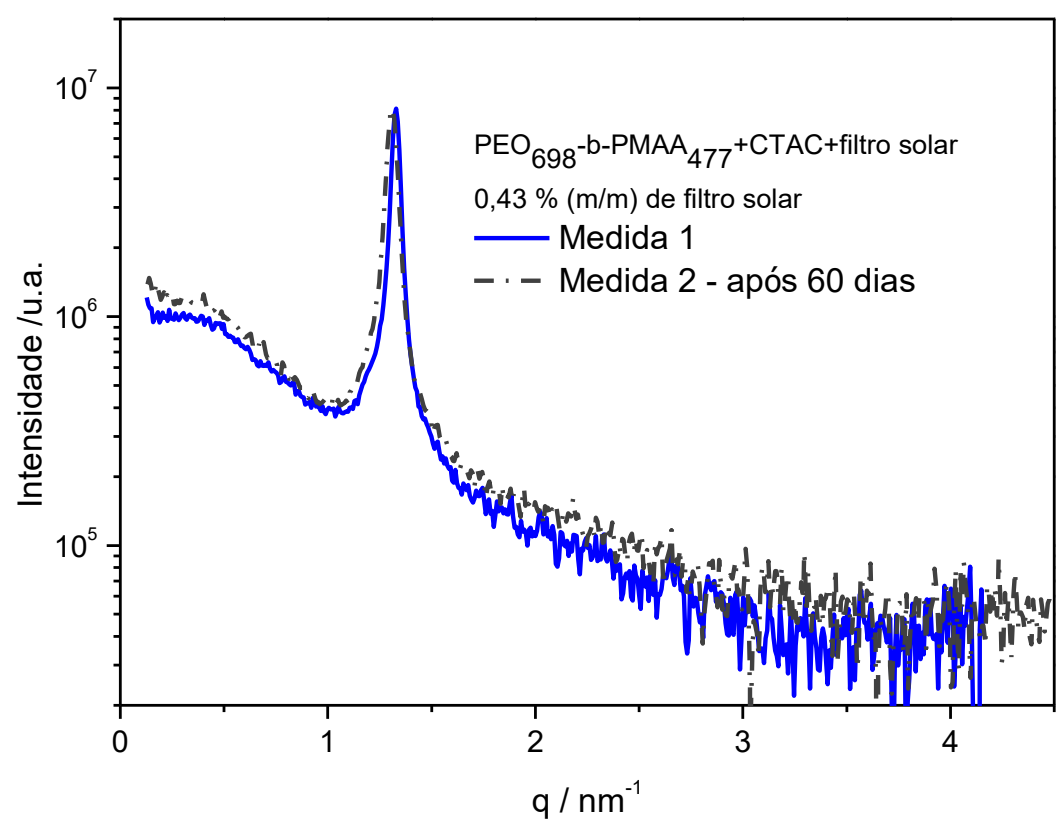

Figura 16: Resultados de SAXS para as nanopartículas do complexo PEO698-b-PMAA477 com a adição de octilmetoxicinamato no intervalo de sessenta dias. 


\section{3.}

Verificação do potencial como formulação de um produto de proteção solar para cabelos.

Perante aos dados obtidos pela caracterização das nanopartículas através das técnicas de SAXS e DLS, foi concluído que a nanopartícula proveniente do complexo $\mathrm{PEO}_{698}-b-\mathrm{PMAA}_{477-C T A C}$ apresenta maior potencial para a formulação de um produto de proteção para cabelos, devido à sua maior capacidade de incorporação de filtro solar e estabilidade superior. Sendo assim, este sistema foi escolhido para o estudo relacionado à aplicação como produto de proteção solar para cabelos. Portanto, os resultados a seguir se referem à amostra proposta como base para a formulação, e que contém 2,5\% (m/m) de PEO698-b-PMAA477-CTAC e $4 \%(\mathrm{~m} / \mathrm{m})$ de octilmetoxicinamato em água.

\subsection{1.}

\section{Aspectos gerais da formulação por observação visual}

A amostra da formulação proposta no presente estudo é líquida, com viscosidade próxima à da água e de cor branca, ou seja, com aspecto muito similar ao leite. A sua baixa viscosidade poderia ser esperada já que a água compõe 93,5 \% $(\mathrm{m} / \mathrm{m})$ da amostra. Estas características garantem uma aplicação e mais fácil por spray, o que leva a uma melhor distribuição na superfície do cabelo, além de evitar o aspecto oleoso como o das formulações em forma de emulsões ou creme. Mas para que a formulação seja eficiente, também é necessário garantir que ocorra uma real deposição sobre os fios e que o efeito de filtrar a radiação solar seja mantido após este processo. Estas características serão avaliadas nas próximas seções.

\subsection{2.}

\section{Avaliação de deposição sobre superfície hidrofílica}

Graças à baixa viscosidade da formulação proposta no presente estudo, é possível realizar sua aplicação por spray. Espectros de absorção 
foram obtidos através da análise de um substrato hidrofílico, no qual a formulação havia sido borrifada. O resultado apresentado na Figura 16 mostra a banda de absorção na região do UVB, confirmando não só a deposição da amostra como sua eficiência em absorver radiação UVB após aplicação.

A análise foi repetida após o substrato ser deixado de molho em água por 30 minutos. Neste caso, a diminuição da intensidade da banda de absorção foi pequena, evidenciando as nanopartículas se aderem a superfícies hidrofílicas efetivamente e a aplicação é resistente à imersão em meio aquoso (a prova d'água). Mesmo após trinta minutos de imersão em água a transmitância da solução varia de 23 a $36 \%$ na faixa do UVB, como pode ser observado na Figura 16. Esta adesão à superfície hidrofílica é esperada devido à casca hidrofílica das nanopartículas, formada pelos blocos de PEO que devem apresentar forte interação com o substrato. Uma vez que ocorre a secagem da amostra, o filtro solar hidrofóbico não é arrastado pela água, uma vez que não é solúvel na mesma.

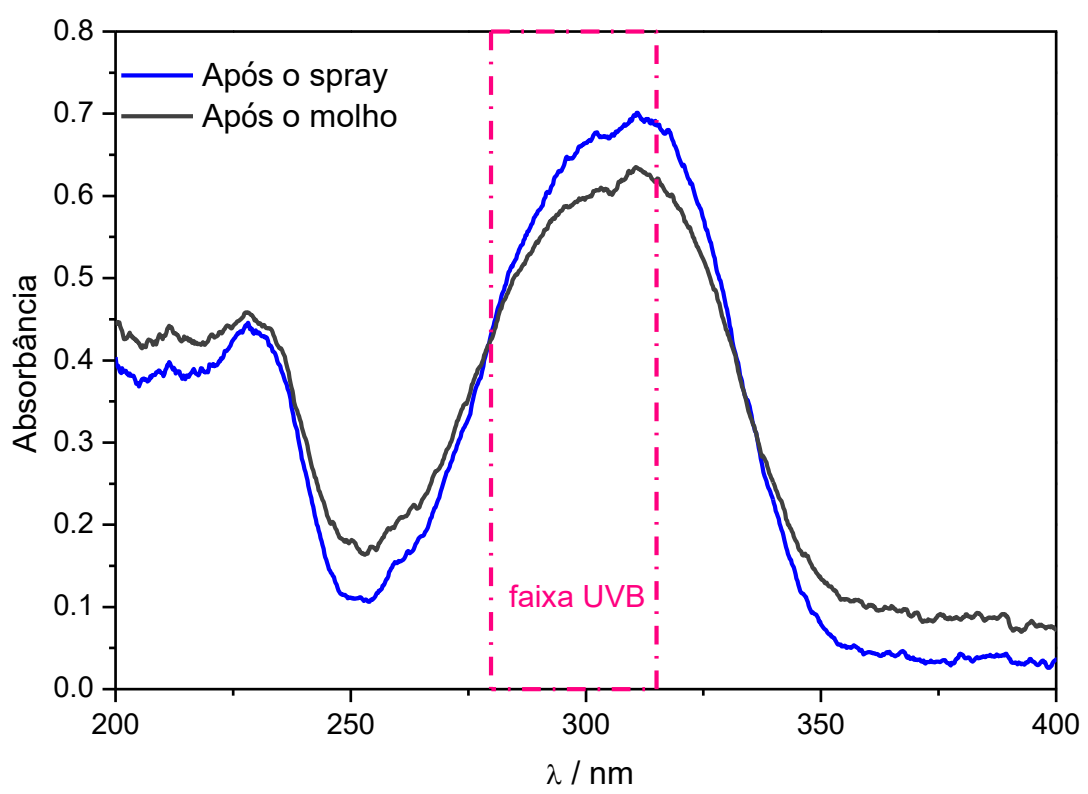

Figura 17: Espectro de absorção resultante do teste de deposição sobre um substrato hidrofílico.

A eficiência da aplicação da amostra por spray sobre um substrato hidrofílico confirma seu potencial como protetor solar para cabelos, uma 
vez que a superfície dos fios se torna cada vez mais hidrofílica quanto mais estão danificados (necessitando de maior proteção) ${ }^{5}$. O fato de ser à prova d'água também é muito desejado, já que os produtos de protetor solar para cabelos são desejados principalmente em ambientes de piscina ou praia, onde ocorre maior exposição ao sol.

\subsection{3.}

\section{Cálculo do fator de protetor solar (FPS) in vitro}

Os produtos de proteção solar geralmente são rotulados com um número chamado fator de proteção solar (FPS), este fator é definido pela Equação 5 como a energia ultravioleta necessária para causar uma dose mínima de eritema na pele com filtro solar, dividida pela energia ultravioleta necessária para causar uma dose mínima de eritema na pele sem filtro solar ${ }^{32}$, ou seja:

$F P S=\frac{\text { Energia } U V \text { para causar um mínimo eritema na pele protegida }}{\text { Energia } U V \text { para causar um mínimo eritema na pele desprotegida }} \quad$ Equação 5

No Brasil, a Agência Nacional de Vigilância Sanitária exige que os todos os cosméticos que declarem apresentar proteção contra radiação solar devem disponibilizar o valor de FPS no rótulo ${ }^{33}$. Entretanto, a maioria dos produtos para cabelos não possui filtro solar na formulação, protegendo apenas contra a desidratação dos fios, e por isso não exibe esta informação no rótulo.

O FPS de produtos tópicos contra a exposição à radiação ultravioleta solar pode ser determinada in vivo ou in vitro, e o ideal é que seja determinada por fototestes em voluntários humanos. Este tipo de determinação vem sendo utilizada durante muitos anos e, embora seja útil e precisa, é um processo demorado, complexo e caro. Muitos estudos foram dedicados ao desenvolvimento de técnicas in vitro para determinar o FPS de compostos protetores solares e foram criados dois tipos de métodos in vitro. O primeiro tipo se refere aos experimentos que envolvem a medição de absorção ou a transmissão de radiação UV de filmes dos 
produtos em placas de quartzo ou biomembranas, enquanto no segundo tipo, a determinação é feita por análise espectrofotométrica de soluções diluídas ${ }^{34}$.

Neste trabalho, foi aplicado um dos métodos mais utilizados que foi proposto por Mansur et al. ${ }^{34}$, no qual utiliza-se medidas de absorbância e aplicam-se os resultados na seguinte equação matemática:

$$
F P S=C F \times \sum_{290}^{320} E E(\lambda) \times I(\lambda) \times A b s(\lambda) \quad \text { Equação } 6
$$

Onde:

EE - espectro de efeito eritemato;

I - espectro de intensidade solar;

Abs - absorbância do protetor;

CF - fator de correção $(=20)$.

Os valores de EE x I para diversos comprimentos de onda já foram determinados em trabalhos prévios e estão apresentados na Tabela $4{ }^{35}$. A absorbância a diferentes comprimentos de onda foi determinada por medidas no espectrofotômetro da amostra proposta para a formulação diluída 20000 vezes e está apresentada na Tabela 5. Já o fator de correção é utilizado para corrigir a medida com respeito à diluição, que neste trabalho foi igual a 20. A diluição é necessária para que a medida não sature o detector do espectrofotômetro. Os dados da Tabela 4 e os resultados de absorbância de cada comprimento de onda foram aplicados à Equação 6 , calculando-se o somatório que corresponde ao valor de FPS da formulação, conforme apresentado na Tabela 5.

Tabela 4: Valores de EE x I normalizados para o cálculo do FPS. Adaptado da referência ${ }^{35}$

\begin{tabular}{cc}
\hline $\boldsymbol{\lambda}(\mathrm{nm})$ & $\begin{array}{c}\text { EE X I } \\
\text { (normalizado) }\end{array}$ \\
\hline 290 & 0,0150 \\
\hline 295 & 0,0817 \\
\hline 300 & 0,2874 \\
\hline 305 & 0,3278 \\
\hline
\end{tabular}




\begin{tabular}{ll}
\hline $\mathbf{3 1 0}$ & 0,1864 \\
\hline $\mathbf{3 1 5}$ & 0,0839 \\
\hline $\mathbf{3 2 0}$ & 0,0180 \\
\hline
\end{tabular}

Através dos valores obtidos neste trabalho que estão expostos na Tabela 5, aplicados a fórmula de fator de proteção solar utilizando espectrofotometria e com o auxílio da tabela desenvolvida por Sayre et al (1979), foi obtido o fator de proteção solar para a formulação igual a 15.

Tabela 5: Valores utilizados para o cálculo do fator de proteção solar

\begin{tabular}{ccc}
\hline $\boldsymbol{\lambda}(\mathbf{n m})$ & Abs & EE x I x Abs \\
\hline $\mathbf{2 9 0}$ & 0,6208 & 0,00931 \\
$\mathbf{2 9 5}$ & 0,6822 & 0,05574 \\
\hline $\mathbf{3 0 0}$ & 0,7208 & 0,20716 \\
$\mathbf{3 0 5}$ & 0,7426 & 0,24342 \\
\hline $\mathbf{3 1 0}$ & 0,7679 & 0,14314 \\
\hline $\mathbf{3 1 5}$ & 0,7932 & 0,06655 \\
\hline $\mathbf{3 2 0}$ & 0,7860 & 0,01415 \\
\hline & Somatório & FPS $=\mathbf{1 5}$
\end{tabular}

O valor de FPS 15 foi calculado apenas in vitro mas confirma que a amostra realmente oferece proteção contra radiação UVB. Se houvesse necessidade de obter um produto com FPS ainda mais alto, poderia ser empregada uma concentração maior de nanopartículas para poder incorporar também uma maior quantidade octilmetoxicinamato.

Quando o valor de FPS é obtido através deste método in vitro que utiliza diluição da amostra, ele corresponde apenas à proteção proveniente do filtro solar orgânico, já que a diluição serve para eliminar os efeitos de espalhamento. Entretanto, a Figura 17 mostra o espectro da formulação em uma concentração mais elevada (porém diluída em relação à original para evitar a saturação do detector), o qual exibe não só a banda de absorção 
no UVB, mas um perfil característico de amostras que apresentam alta intensidade de espalhamento de luz. Isto também pode ser observado visualmente por se tratar de uma amostra branca. Deste modo, é possível afirmar que a formulação do filtro solar apresenta características de protetores orgânicos (ou químicos), mas também de protetores inorgânicos (ou físicos), devido ao espalhamento de luz proveniente das nanopartículas, que neste caso específico são nanopartículas orgânicas. Isto faz com que a formulação proteja também contra a radiação UVA, UVC e visível, já que o espalhamento ocorre em uma ampla faixa do espectro. Vale notar também que a amostra contendo apenas nanopartículas apresenta uma banda de absorção na região do UVC proveniente do complexo PEO698-b-PMAA477-CTAC.

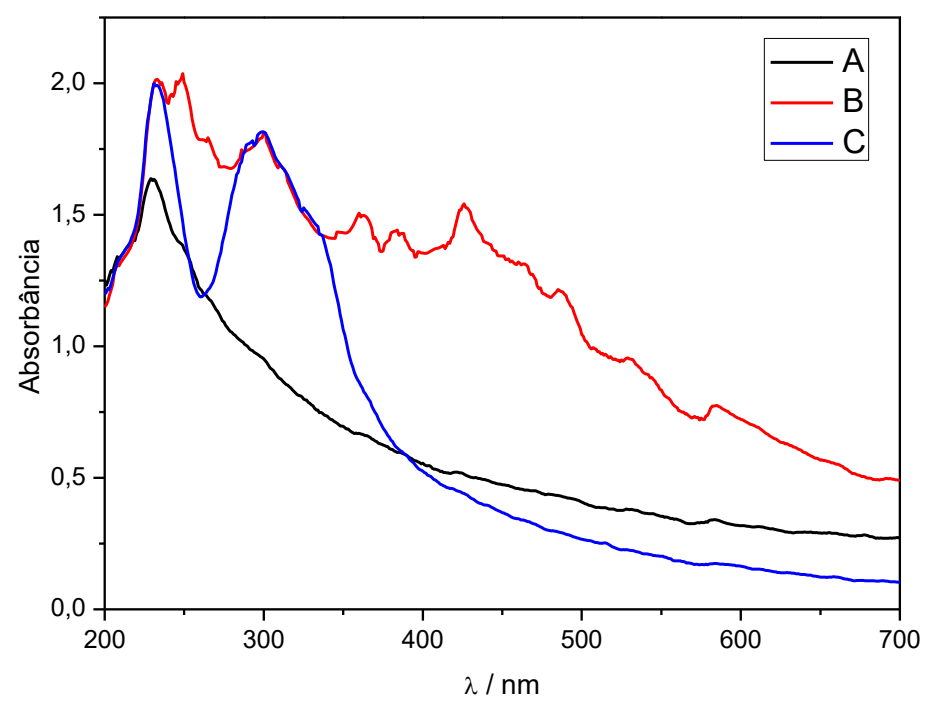

Figura 18: Espectro de absorbância normalizada de amostras contendo: $A$ - nanopartículas do complexo PEO698-b-PMAA477-CTAC a 2,5\% (m/m) em água; $B$ - amostra $A$ após adição de 0,33\% $(\mathrm{m} / \mathrm{m})$ de octilmetoxicinamato, seguida de diluição a 25 vezes; $C$ - amostra $A$ após após adição de $0,33 \%(\mathrm{~m} / \mathrm{m})$ de octilmetoxicinamato, seguida de diluição 125 vezes.

\subsection{4.}

\section{Avaliação da proteção contra radiação em cabelos humanos}

Tendo em vista que o octilmetoxicinamato é um filtro para radiação UVB, ele evita a degradação de proteína, na qual os aminoácidos cistina 
são oxidados a ácido cisteico. Para avaliar esta degradação, foi utilizado o método proposto por Signori e Lewis ${ }^{36}$. Para isso, foram realizadas análises de espectroscopia de absorção no infravermelho por transformada de Fourier (FTIR) em cabelos humanos, acompanhando a banda característica do ácido cisteico, referente ao estiramento da ligação S-O em $1042 \mathrm{~cm}^{-1}$.

O espectro típico de cabelos apresenta principalmente às bandas típicas de aminoácidos, uma vez que eles são compostos principalmente por proteínas (Figura 18). Muitas das principais bandas dos componentes da formulação proposta neste trabalho se sobrepõem às bandas dos aminoácidos, como pode ser observado no espectro obtido a partir de mechas de cabelos após a aplicação da amostra (Figura 18). A Tabela 6 apresenta as principais bandas do espectro de absorção no infravermelho médio atribuídas a aminoácidos, referentes a aminas e ácidos carboxílicos, do ácido cisteico e as bandas referentes aos compostos presentes na formulação proposta.

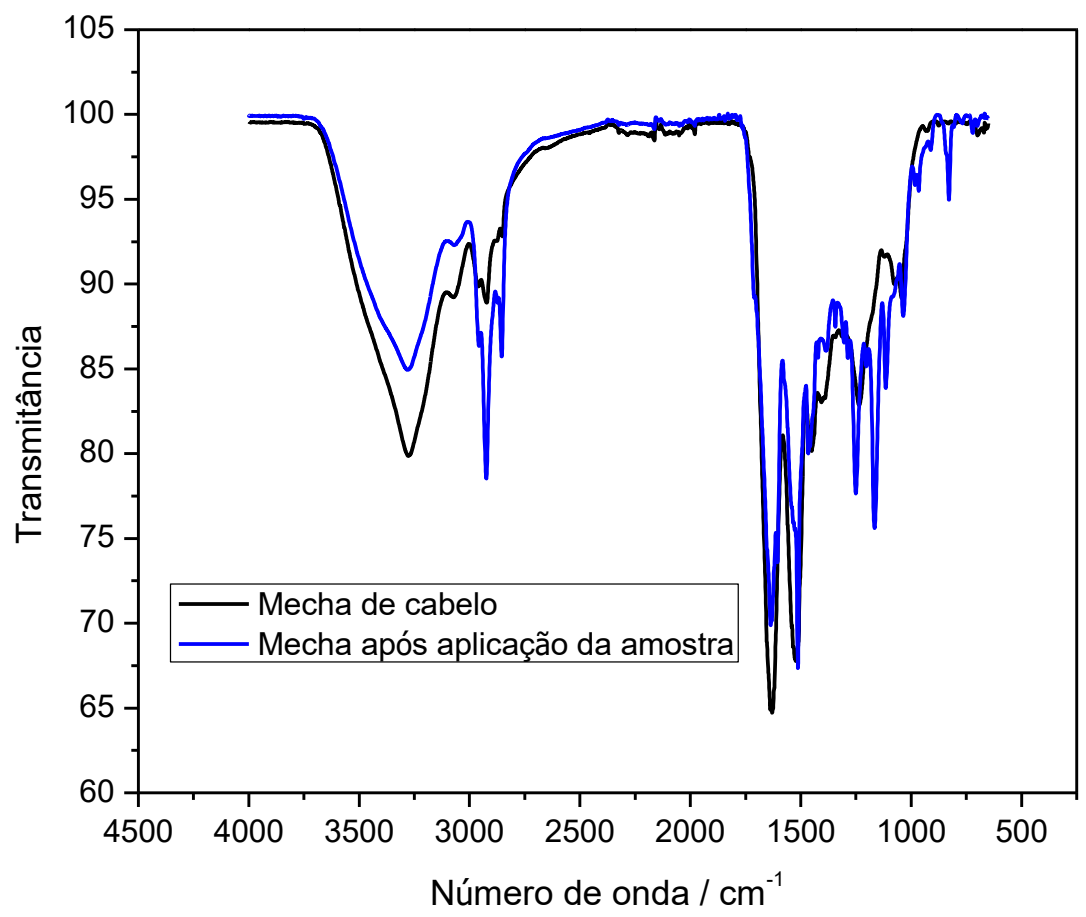

Figura 19: Espectro de FTIR de mechas de cabelo ante e após aplicação da formulação de protetor solar

Para avaliar a degradação do cabelo por FTIR, é necessário 
normalizar o espectro, calcular a absorbância da banda do ácido cisteico e fazer a normalização em relação a uma banda que não tenha grande variação, como a do estiramento do $\mathrm{CH}_{2} \mathrm{em} 1450 \mathrm{~cm}^{-1}$ que é sugerida no trabalho de referência ${ }^{36}$. Assim, é calculada a razão das transmitâncias do ácido cisteico e do $\mathrm{CH}_{2}$, que chamaremos de Abs1042/Abs 1450 . Entretanto, é possível observar nas Figura 18 que a formulação interfere em quase todos os sinais do espectro da mecha de cabelo. Por isso, é necessário também verificar o efeito da adição do protetor no valor de Abs 1042/Abs $_{1450}$, para ter uma análise que sirva como branco. Os valores da razão Abs 1042/Abs 1450 foram calculados a partir da análise de mechas de cabelo antes e depois de diferentes tratamentos. O gráfico de barras da Figura 19 mostra o aumento relativo que os valores de Abs 1042/Abs 1450 sofreram após cada um dos diferentes tratamentos.

Tabela 6: Principais bandas do espectro de absorção do infravermelho a serem acompanhadas nos espectros deste trabalho.

\begin{tabular}{|c|c|c|}
\hline Composto & Atribuição & Banda $\left(\mathrm{cm}^{-1}\right)$ \\
\hline \multirow{5}{*}{ Aminoácidos } & C-N Amina & $1350-1000$ \\
\hline & $\mathrm{N}-\mathrm{H}$ & $3500-3100$ \\
\hline & $\mathrm{C}=\mathrm{O}$ ác. Carboxílico & $1725-1700$ \\
\hline & -OH ácido carboxílico & $3400-2400$ \\
\hline & C-O ácido carboxílico & $1300-1000$ \\
\hline Ácido Cisteico & $\mathrm{S}-\mathrm{O}$ & 1044 \\
\hline \multirow{4}{*}{ PMAA } & $\mathrm{C}=\mathrm{O}$ & 1700 \\
\hline & $-\mathrm{OH}$ & 2590 \\
\hline & $-\mathrm{CH}_{3}$ & 2990 \\
\hline & $-\mathrm{CH}_{2}$ & 2930 \\
\hline \multirow[t]{2}{*}{ PEO } & $\mathrm{C}-\mathrm{O}$ & 1715 \\
\hline & $\mathrm{CH}_{2}$ & $2960-2850$ \\
\hline \multirow[t]{2}{*}{ CTAC } & $\mathrm{CH}_{3}$ & $1390-1370$ \\
\hline & $\mathrm{C}-\mathrm{N}^{+}$ & 1473 \\
\hline
\end{tabular}




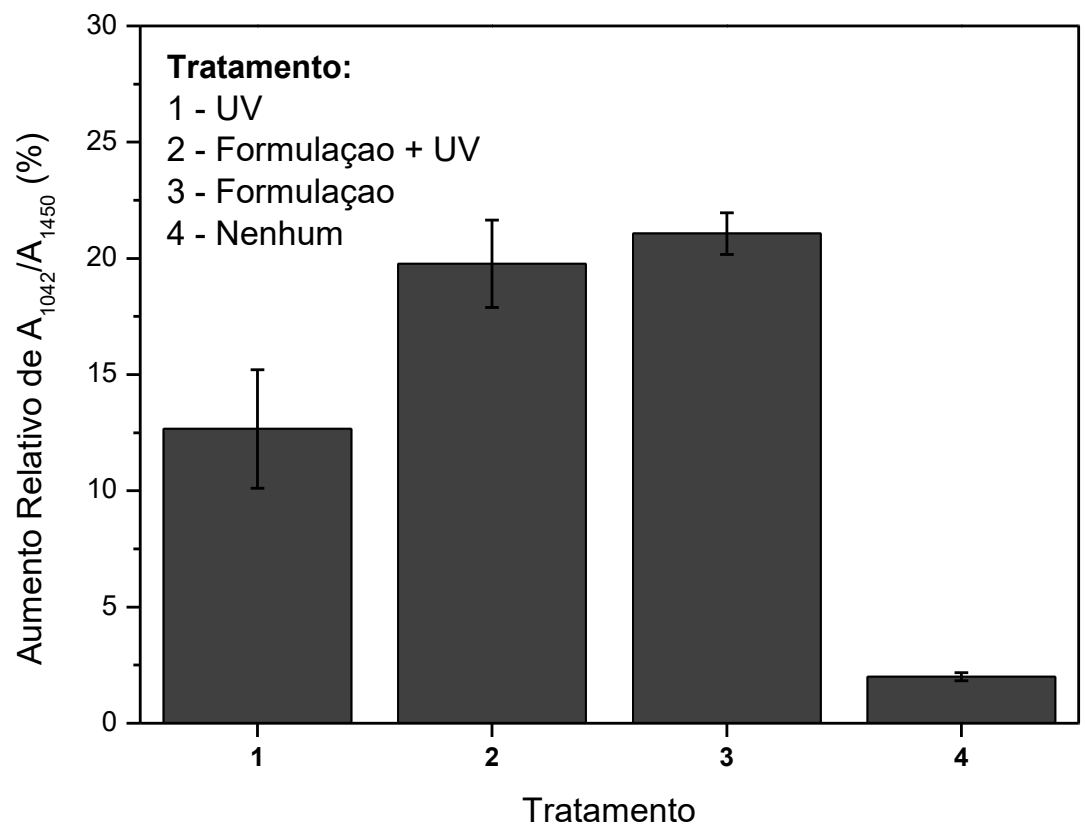

Figura 20: Valores do aumento relativo na razão entre as absorbâncias das bandas de ácido cisteico $\left(1042 \mathrm{~cm}^{-1}\right)$ e $\mathrm{CH}_{2}\left(1450 \mathrm{~cm}^{-1}\right)$ após diferentes tratamentos.

As mechas de cabelo que passaram pelo Tratamento 1 foram expostas à radiação ultravioleta sem a aplicação da formulação, enquanto no Tratamento 2 as mechas sofreram a mesma exposição, porém com a aplicação da formulação por spray. O Tratamento 3 consistiu apenas da aplicação da formulação, porém sem a exposição à radiação ultravioleta, para a utilização do resultado como branco. Finalmente, no Tratamento 4 as mechas foram apenas reanalisadas sem passar por aplicação da formulação e nem exposição à radiação, para verificar a reprodutibilidade do método. Como é possível observar pela Figura 19, a exposição sem proteção leva a um aumento relativo de $13 \%$ da banda normalizada do ácido cisteico, indicando um aumento deste aminoácido na mecha devido à degradação (Tratamento 1). Nos dois casos em que foi aplicada a formulação (Tratamentos 2 e 3), os valores de aumento relativo foram muito parecidos, de 20 e $21 \%$, indicando que esta variação se deu apenas devido à presença do protetor. Desta forma, pode-se concluir que não houve aumento significativo da quantidade de ácido cisteico nas mechas em que a formulação foi aplicada antes da exposição à radiação. Ou seja, a 
formulação evitou que os fios de cabelo sofressem degradação por perda proteica, comprovando sua eficácia como protetor solar. 


\section{5.}

\section{CONCLUSÕES}

O presente trabalho resultou no preparo e caracterização de amostras aquosas de nanopartículas do tipo núcleo-casca, nas quais foi incorporado um filtro solar orgânico. Através disso foi possível propor uma formulação com características adequadas para um produto de proteção solar para cabelos.

As nanopartículas formadas por copolímeros dibloco e surfactantes de cargas opostas se demonstraram úteis para incorporar moléculas hidrofóbicas, dispersando-as em meio aquoso. A fração mássica do óleo octilmetoxicinamato que pode ser incorporada (até $4 \%$ ) é superior do que a das próprias nanopartículas $(2,5 \%)$.

Observou-se que o comprimento de ambos os blocos do copolímero tem papel fundamental para a incorporação nas nanopartículas. O bloco aniônico deve ser longo o suficiente para neutralizar um grande número de micelas catiônicas no núcleo, permitindo a incorporação de uma grande quantidade de moléculas hidrofóbicas. Além disso, o maior número de micelas permite que as mesmas se organizem a longo alcance formando um núcleo líquido-cristalino. Por sua vez, o bloco hidrofílico neutro deve ter um comprimento longo o bastante para estabilizar as nanopartículas em meio aquoso. Por isso, dentre os sistemas testados, o que apresentou maior potencial para aplicação foi o $\mathrm{PEO}_{698}-b$-PMAA $477-C T A C$, por possuir ambos os blocos longos.

A incorporação de moléculas de octilmetoxicinamato causa mudanças na estrutura do núcleo observada pela técnica de SAXS. Isto levou a uma diminuição da curvatura das micelas, o que demonstra que o óleo atua como um cosurfactante. Entretanto, outros óleos com diferentes estruturas moleculares poderiam atuar de formas diferentes, o que já vem sendo estudado no nosso grupo, utilizando óleos essenciais de plantas com propriedades repelentes. Já a técnica de DLS mostrou que a adição de octilmetoxicinamato não causa variação significativa no tamanho das nanopartículas, e que no caso do PEO698-b-PMAA477-CTAC, elas apresentam estabilidade superior ao longo do tempo comparado às 
nanopartículas na ausência do óleo.

Com base nos resultados obtidos, foi proposta uma formulação

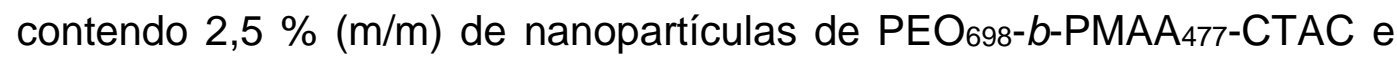
$4 \%(\mathrm{~m} / \mathrm{m})$ de octilmetoxicinamato. A avaliação das propriedades físicoquímicas permitiu concluir que esta amostra possui baixa viscosidade e alta adesão a superfícies hidrofílicas, sendo facilmente aplicada por spray e a prova d'água. Ela também apresenta características de protetor químico, com absorção na região do UVB, e de protetor físico, devido a alta intensidade de espalhamento de luz das nanopartículas. O cálculo do fator de proteção solar por método in vitro indicou que a amostra possui FPS = 15. Finalmente, testes preliminares com cabelos indicaram que a amostra é capaz de evitar a perda proteica decorrente da exposição à radiação UVB. Obviamente, para a efetiva implementação desta formulação como produto no mercado de cosméticos seria necessária a continuação desta pesquisa com a realização de mais experimentos. Entre eles, podemos citar a realização de testes com outros aditivos que podem ser necessários à formulação, como estabilizantes, fragrâncias, corantes e reguladores de pH. A partir da formulação final, seria necessário realizar testes de segurança (irritação, sensibilização, toxicidade), avaliação de desempenho e análise sensorial.

Até o momento, este estudo já demonstra o grande potencial de aplicação dos complexos de copolímeros diblocos e surfactantes de cargas opostas que formam nanopartículas núcleo-casca. Este potencial não se restringe à formulação de um protetor solar para cabelos, mas pode ser estendida para outras áreas onde se deseja incorporar uma grande quantidade de ativo hidrofóbico em meio aquoso, utilizando uma pequena quantidade de veículo. Além disso, o estudo permitiu compreender o papel de cada bloco do copolímero e as alterações causadas pelo octilmetoxicinamato na estrutura das nanopartículas. Estas informações podem facilitar o desenvolvimento de outras pesquisas, indicando as melhores características das moléculas para obter as propriedades adequadas para uma determinada aplicação. Portanto, este trabalho traz uma contribuição científica com aspectos acadêmicos e tecnológicos importantes. 
6.

\section{REFERÊNCIAS BIBLIOGRÁFICAS}

(1) MORIOKA, K. Hair Follicle Differentiation Under the Electron Microscope, $1^{\circ}$.; Springer: Tokyo, 2014.

(2) PISONI, A. C. Dificuldades Vivenciadas por Mulheres em Tratamento para o Câncer de Mama, Universidade Regional do Noroeste do Estado do Rio Grande do Sul - Unijuí, 2012.

(3) NOGueiRA, A. C. S.; DICELIO, L. E.; JOEKES, I. About PhotoDamage of Human Hair. Photochem. Photobiol. Sci. 2006, 5 (2), p.165-169.

(4) NOGUEIRA, A. C. S. Foto-Degradação Do Cabelo: Influência Da Pigmentação Da Fibra, Universidade Estadual de Campinas, 2008.

(5) ROBBINS, C. R. Chemical and Physical Behavior of Human Hair; Springer Berlin Heidelberg: Berlin, Heidelberg, 2012.

(6) BAGATIN, E. Mecanismos Do Envelhecimento Cutâneo E O Papel Dos Cosmecêuticos. Revista Brasileira de Medicina. August 2017, p. 5-11.

(7) SANTOS NOGUEIRA, A. C.; Joekes, I. Hair Color Changes and Protein Damage Caused by Ultraviolet Radiation. J. Photochem. Photobiol. B Biol. 2004, 74 (2-3), p.109-117.

(8) TRÜEB, R. M.; TOBIN, D. J. Aging Hair; Springer Berlin Heidelberg: Berlin, Heidelberg, 2010.

(9) VANEMON, P. Proteção Dos Cabelos. Cosmetics \& Toiletries Brasil. April 2000, p. 84.

(10) TOPAN, J. F. Emulsões À Base de Óleo de Girassol ( Helianthus Annus L .) Com Cristal Líquido: Avaliação Das Propriedades Físico-Químicas E Atividade Cosmética., Universidade de São Paulo, 2012.

(11) FLOR, J.; DAVOLOS, M. Protetores Solares. Química Nova. August 2006.

(12) CABRAL, L. D. DA S.; PEREIRA, S. DE O.; PARTATA, A. K. Filtros Solares E Fotoprotetores Mais Utilizados Nas Formulações No Brasil. Revista Científica do ITPAC. Araguaína July 2011. 
(13) MANO, E. B.; MENDES, L. C. Introdução a Polímeros; Editora Edgard Blücher Ltda: São Paulo, 2004.

(14) MAGALHÃES, M.. Tudo Que Você Faz Tem Haver Com Química, 1st ed.; Livraria da Física Editora: São Paulo, 2015.

(15) HOLMBERG, K.; JÖNSSON, B.; KRONBERG, B.; LINDMAN, B. Surfactants and Polymers in Aqueous Solution; John Wiley \& Sons, Ltd: Chichester, UK, 2002.

(16) DALTIN, D. Tensoativos: Química, Propriedades E Aplicações, 1st ed.; Editora Edgard Blücher Ltda: São Paulo, 2012.

(17) KROIN, T. Cristais Líquidos. Caderno de Brasileiro de Ensino de Física. Florianópolis April 1985.

(18) POLETTO, F. S.; LIMA, F. S.; LUNDBERG, D.; NYLANDER, T.; LOH, W. Tailoring the Internal Structure of Liquid Crystalline Nanoparticles Responsive to Fungal Lipases: A Potential Platform for Sustained Drug Release. Colloids Surfaces $B$ Biointerfaces 2016, 147, p.210-216.

(19) PERCEBOM, A. M.; JANIAK, J.; SCHILLÉN, K.; PICULELL, L.; LOH, W. Micellization of Water-Soluble Complex Salts of an lonic Surfactant with Hairy Polymeric Counterions. Soft Matter 2013, 9 (2), p.515-526.

(20) VITORAZI, L.; BERRET, J. F.; LOH, W. Self-Assembly of Complex Salts of Cationic Surfactants and Anionic-Neutral Block Copolymers. Dispersions with Liquid-Crystalline Internal Structure. Langmuir 2013, 29 (46), p.14024-14033.

(21) PERCEBOM, A. M.; BARBOSA, L. R. S.; ITRI, R.; LOH, W. How Does the Ethoxylated Grafting of Polyelectrolytes Affect the SelfAssembly of Polyanion-Cationic Surfactant Complex Salts? Langmuir 2014, 30 (39), p.11493-11503.

(22) BERRET, J. F.; CRISTOBAL, G.; HERVÉ, P.; OBERDISSE, J.; GRILLO, I. Structure of Colloidal Complexes Obtained from Neutral/polyelectrolyte Copolymers and Oppositely Charged Surfactants. Eur. Phys. J. E 2002, 9 (4), p.301-311. 
(23) BERRET, J. F.; VIGOLO, B.; ENG, R.; HERVÉ, P.; GRILLO, I.; YANG, L. Electrostatic Self-Assembly of Oppositely Charged Copolymers and Surfactants: A Light, Neutron, and X-Ray Scattering Study. Macromolecules 2004, 37 (13), p.4922-4930.

(24) CLAUZEL, M.; JOHNSON, E. S.; NYLANDER, T.; PANANDIKER, R. K.; SIVIK, M. R.; PICULELL, L. Surface Deposition and Phase Behavior of Oppositely Charged Polyion À Surfactant Ion Complexes . Delivery of Silicone Oil Emulsions to Hydrophobic and Hydrophilic Surfaces. ACS Apllied Maeterials and interfaces. Cincinnati July 2011, p. 2451-2462.

(25) SCHÄRTL, W. Light Scattering from Polymer Solutions and Nanoparticle Dispersions; Springer Laboratory; Springer Berlin Heidelberg: Berlin, Heidelberg, 2007.

(26) SCHNABLEGGER, H.; SINGH, Y. The SAXS Guide: Getting Acquainted with the Principles, 3rd ed.; Anton Paar GmbH, 2013.

(27) PAVIA, D. L.; LAMPMAN, G.; KRIZ, G.; VYVYAN, J. Introdução a Espectroscopia, 4th ed.; Cengage Learning: Washington, 2001.

(28) SANTIAGO, P. S.; NETO, D. DE S.; BARBOSA, L. R. S.; ITRI, R.; TABAK, M. Interaction of Meso-Tetrakis (4-Sulfonatophenyl) Porphyrin with Cationic CTAC Micelles Investigated by Small Angle X-Ray Scattering (SAXS) and Electron Paramagnetic Resonance (EPR). J. Colloid Interface Sci. 2007, 316 (2), p.730-740.

(29) BERNARDES, J. S.; LOH, W. Structure and Phase Equilibria of Mixtures of the Complex Salt Hexadecyltrimethylammonium Polymethacrylate, Water and Different Oils. J. Colloid Interface Sci. 2008, 318 (2), p.411-420.

(30) FERREIRA, G. A.; PICULELL, L.; LOH, W. Addition of N -Alcohols Induces a Variety of Liquid-Crystalline Structures in SurfactantRich Cores of Dispersed Block Copolymer/Surfactant Nanoparticles. ACS Omega 2016, 1 (6), p.1104-1113.

(31) SILVA, A. M. P. S. Autoassociação de Sais Complexos de Surfatantes e Copolímeros Aleatórios e Enxertados, Universidade Estadual de Campinas, 2012.

(32) DUTRA, E. A.; ALMANÇA, D.; KEDOR-, E. R. M.; INÊS, M.; 
MIRITELLO, R. Determination of Sun Protection Factor ( SPF ) of Sunscreens by Ultraviolet Spectrophotometry. Brazilian J. Pharm. Sci. 2004, 40 (3), p.381-385.

(33) Agência Nacional de Vigilância Sanitária - ANVISA RESOLUÇÃO RESOLUÇÃO DA DIRETORIA COLEGIADA-RDC N ${ }^{\circ} 30$, DE 1 DE JUNHO DE 2012 Ministério Da Saúde - MS Agência Nacional de Vigilância Sanitária - ANVISA; 2012.

(34) MANSUR, J. S.; BREDER, M. N. R.; MANSUR, M. C. A.; AZULAY, R. D. Determinação Do Fator de Proteção Solar Por Espectrofotometria. An. Bras. Dermatol. Rio de Janeiro 1986, p.121-124.

(35) SAYRE, R. M.; AGIN, P. P.; VEE, G. J. LE; MARLOWE, E. A Comparison of In Vivo and In Vitro Testing of Sunscreening Formulas. Phytochem. Photobiol. 1979, 29,p. 559-566.

(36) SIGNORI, V.; LEWIS, D. M. FTIR Investigation of the Damage Produced on Human Hair by Weathering and Bleaching Processes: Implementation of Different Sampling Techniques and Data Processing. Int. J. Cosmet. Sci. 1997, 19 (1), p.1-13. 